\title{
Tooth surface mismatch modification method of cycloidal bevel gear based on conjugate tooth surface modification
}

\author{
Jing DENG*, Shaowu NIE**, Xiaozhong DENG** and Chuang JIANG** \\ * Management School, Henan University of Science and Technology, Luoyang, Henan Province, \\ 48 Xiyuan Rd, Luoyang 471003, China \\ ** Collaborative Innovation Center of Machinery Equipment Advanced Manufacturing of Henan Province, \\ 48 Xiyuan Rd, Luoyang 471003, China \\ E-mail: dxz01@163.com
}

Received: 16 June 2019; Revised: 21 October 2019; Accepted: 22 January 2020

\begin{abstract}
In order to obtain locally conjugated tooth surface contact, a tooth surface mismatch modification method is proposed based on the fully conjugated characteristics of cycloidal bevel gear. Firstly, according to the principle of fully conjugated, the mathematical model for calculating the cutting parameters of cycloidal bevel gear is established, and the calculating method of the cutting parameters of the fully conjugated tooth surface is deduced. Secondly, the double crowned tooth surface modification method is studied, and the tooth length direction modification is realized by modifying the radius of the cutter blade edge, and the tooth profile direction modification is realized by modifying the shape of cutter blade edge, so that the fully conjugated tooth surfaces meshing with each other are mismatched in the directions of tooth length and tooth profile. On this basis, the mismatch coefficients of tooth surface are calculated by means of polynomial expression of second order. Five coefficients in the mismatch relationship of tooth surface are corrected to modify the tooth surface of pinion again, and the original cutting parameters of pinion are corrected. And then, the required mismatch relationship of tooth surface is obtained. Finally, a pair of cycloidal bevel gear is analyzed in the process of tooth surface mismatch modification. The results of gear cutting experiments are consistent with the simulation results, which verify the effectiveness and feasibility of the proposed tooth surface mismatch modification method.
\end{abstract}

Keywords : Cycloidal bevel gear, Fully conjugated, Tooth surface mismatch, Double crowned, Mismatch modification

\section{Introduction}

Cycloidal bevel gear is processed by continuous indexing and double sides method, which have the advantages of high cutting efficiency, good strength and low noise, and are widely used in automotive drive axles. Cycloidal bevel gear is the key transmission components of automotive driving axles. The meshing quality of their tooth surfaces directly affects the transmission performance of automobiles. In order to reduce the vibration and noise of gears, as an effective means, tooth surface modification technology has been gradually applied in the design and processing of bevel gears. Relevant scholars at home and abroad have done a lot of researches on the tooth surface modification technology. Liu et al. (2008) modified the tooth profile of spiral bevel gear with parabolic blade, and studied the influence of parabolic modification on the meshing quality of spiral bevel gear. Nie et al. $(2012,2013)$ studied the influence of blade profile modification with arc profile and high-order curve profile modification on the contact area and transmission error of cycloidal bevel gear. Zhang et al. (2018) studied the influence of cutter arc modification on the meshing performance of spiral bevel gear with duplex helical method. Huang et al. (2017) established the mathematical model of spiral bevel gear circular arc cutter, and studied the influence of circular arc cutter on the tooth contact performance of spiral bevel gear. These studies focus on the edge profile modification of cutters, and mainly to 
achieve tooth profile modification, which can optimize transmission error and reduce the sensitivity of tooth profile direction to the mounting errors.

In order to modify the tooth surface more flexibly, in recent years, the related scholars have gradually turned to the control of the tooth surface topology structure for the research of tooth surface modification technology (Peng et al., 2014; Jiang et al., 2014; Su et al., 2012; Su et al., 2012) studied the tooth surface modification method of spiral bevel gear. The target tooth surface of pinion was constructed by preset coincidence degree, transmission error and contact ellipse parameters, so as to realize the modification of the tooth surface of pinion. Cao et al. (2015) studied the design method of tooth surface topology structure for high-order transmission error of aeronautical spiral bevel gears. Shih et al. (2010) proposed a topological modification method for spiral bevel gear based on ease off. The modification tooth surface of pinion was constructed by preset meshing performance. Nie et al. (2018) proposed a tooth surface modification method based on tooth surface mismatch control for spiral bevel gear. The tooth surface topology of pinion was modified by improving the mismatch relationship of tooth surface. Du et al. (2015) constructed a pinion target tooth surface topology by presetting transmission error and contact marks for cycloidal hypoid gear, and realized the active design of tooth surface. Aiming at the double helix method, Yan et al. (2019) constructed the target tooth surface topology of the pinion by zoning parabolic modification of the tooth surface, which realized the modification of pinion tooth surface and improved the meshing performance of the tooth surface. Jiang et al. (2019) combined LTCA and tooth surface friction theory to study the multi-objective optimization design method for hypoid gear with ease off topological modification. These research results provided theoretical guidance for the free modification of the whole tooth surface and the flexible control of the meshing performance of the tooth surface.

Based on the researches of predecessors, a comprehensive modification method for tooth surface mismatch of cycloidal bevel gear is proposed in this paper. Based on the characteristics of fully conjugated of cycloidal bevel gear, the double crowned of tooth surface is realized by calculating the parameters of fully conjugated cutting, and then the topological modification of pinion tooth surface is optimized by combining the modification technology of tooth surface mismatch. Finally, the required meshing performance of tooth surface is obtained.

\section{Calculating the cutting parameters of conjugated tooth surface}

\subsection{Fully conjugated tooth surface}

During the process of tooth surface design and manufacturing of cycloidal bevel gear, the cutter head structure and parameters play a very important role, and there are many parameters defined in the cutter head. In order to make these parameters easier to understand, here we firstly give the cutter head structure,as shown in Fig. 1.From Fig. 1, it can be seen that the projective line of cutter blade edge located at the end surface of cutter head doesn't cross through the center of cutter head, but is tangent to one circle,and the tangency point is point $E$. There have two main reference planes in the cutter head of cycloidal bevel gear,one is the pitch point plane $T$ of cutter head which is vertical to the cutter head axis and cross through the pitch point of cutter blade edge, and the pitch point is $P_{A}$ for outer blade edge, and $P_{I}$ for inner blade edge. The other plane is plane $H$ which cross through cutter blade edge and its projective line, and the shape of cutter blade edge is described in the plane $H$.

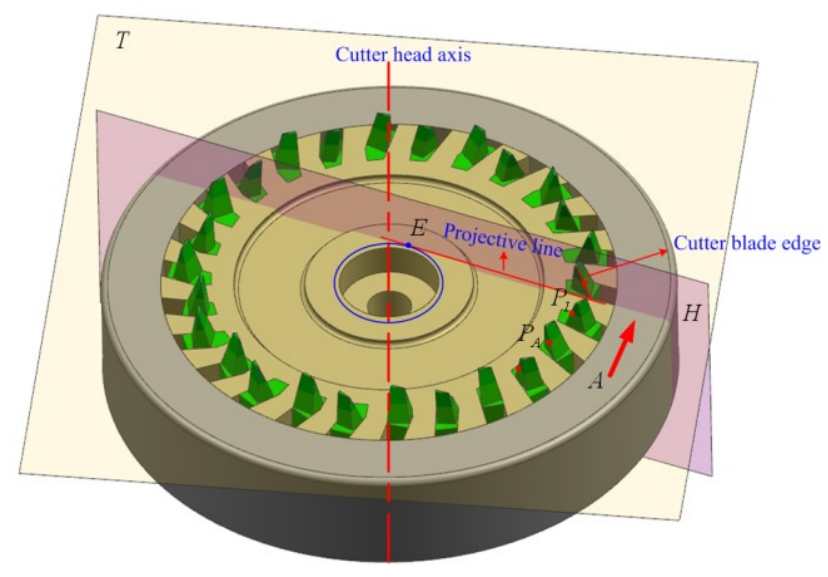

Fig. 1 Cutter head structure of cycloidal bevel gear 
Cycloidal bevel gear is machined based on the principle of crown generating gear. The cutter head axis of pinion and gear can be parallel to each other. When the pinion and the gear are assembled together, the relationship between the cutters of pinion and gear can be shown in Fig. 2.

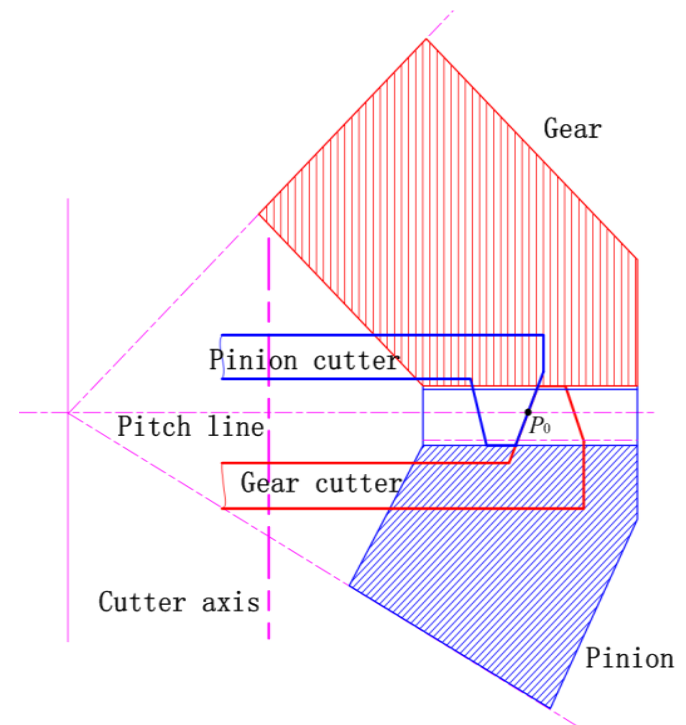

Fig. 2 The principle of fully conjugated

In Fig.2, the point $P_{0}$ is called cutter nominal pitch point. When the cutter radius is not corrected, the point $P_{A}$ and $P_{I}$ in Fig.1 are all coincided with point $P_{0}$. From Fig.2, it can be seen that on the plane of pitch line of tooth, when the radius of pinion outer cutter is equal to the radius of gear inner cutter, and their tooth profile angles are also equal, the generating gear convex formed by pinion outer cutter and the generating gear concave formed by gear inner cutter can form dual tooth surface, so the pinion concave is in line contact with the gear convex. That is, the pinion concave and gear convex are fully conjugated. Similarly, when the radius of pinion inner cutter is equal to the radius of gear outer cutter and their tooth profile angles are also equal, the pinion convex is fully conjugated with the gear concave.

\subsection{Calculating model of cutting tooth}

According to the principle of fully conjugated, the cutter head axis of gear and pinion should be coincident with each other and parallel to the axis of the imaginary cradle, and the tooth surfaces of the generating gear should be completely dual. Figure 3 shows the position relationship among the cutter head, the generating gear and the workpiece in the processing of the right hand gear. For the processing left hand pinion, the cutter head axis is located in the fourth quadrant, and the corresponding position relationship can be established with a similar method.

As shown in Fig. 3, the projection lines of outer blade edge and inner blade edge in the axial section of cutter head are intersected at cutter nominal pitch point $P_{0}$. The pitch point plane $T$ is vertical to the cutter head axis and cross through point $P_{0}$, and it is also called the machine plane. The point $M$ is the selected reference point for calculating machine setting parameters, and this point corresponds to the cutter pitch point $P_{0}$ of the cutter head. The vector coordinate axes $i$ and $j$ are located in the plane $T$. The intersection point of the axis of the generating gear and the indexing plane is $O_{p}$, and the center of the cutter head is $O_{0}$. In the machine plane, the pedal of the common perpendicular line between the axis of the generating gear and the pitch cone line is point $B$, and the pedal of the common perpendicular line between the axis of the generating gear and the axis of the gear is point $A$, which is also called the cross point of gear cutting. $O_{2}^{\prime}$ is the vertex of the gear pitch cone, $\mathrm{O}_{2}$ is the design cross point of gear. In this figure, $\delta_{0}$ is the direction angle of cutter edge, $r_{0}$ is the nominal radius of cutter head, $\beta_{m 2}$ is the spiral angle of reference point of gear, $\beta_{p}$ is the spiral angle of reference point of generating gear, $R_{p}$ is the cone distance of reference point of generating gear, $R_{m 2}$ is the cone distance of gear of reference point, $\varepsilon_{02}$ is the deviation angle of gear cutting, and $Z_{r^{2}}$ is the pitch apex distance of gear. The basic processing parameters for gear cutting include: radial setting $E_{x 2}$, basic cradle angle $q_{2}$, vertical offset $E_{m 2}$, sliding base setting modification $X_{b 2}$, increment of machine center to back $X_{q 2}$, roll ratio $m_{p 2}$, speed ratio of tooth dividing $i_{p 2}$, and machine root angle $\delta_{M 2}$. 

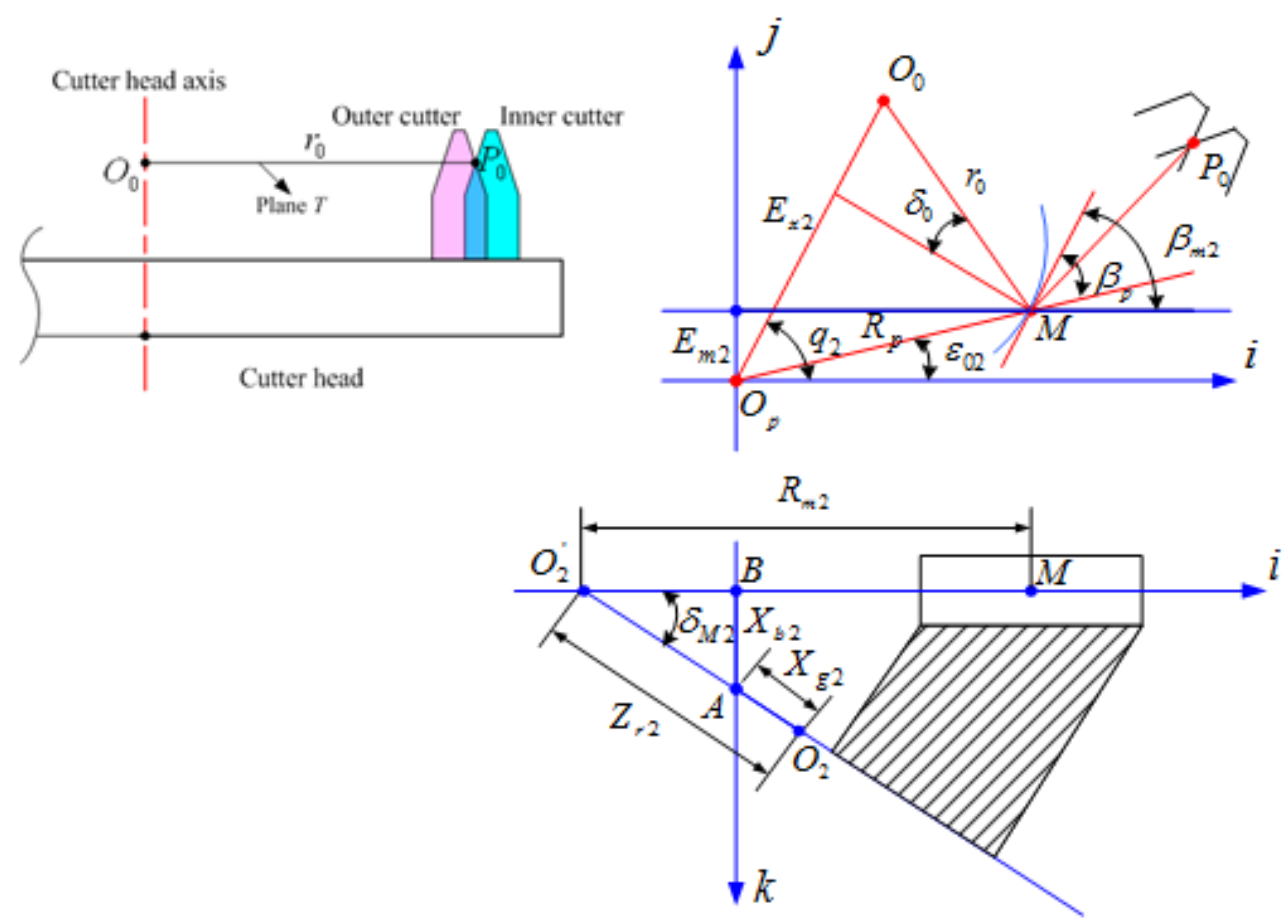

Fig. 3 Calculating model of right hand gear cutting

Assuming that the tooth number of gear is $z_{2}$, and the tooth number of generating gear is $z_{p 2}$, and the tooth number of cutter head is $z_{0}$, and the pitch angle of gear is $\delta_{2}$, and the reference point radius of gear pitch circle is $r_{m 2}$.According to the geometric position relationship in Fig.3, the formulas for calculating the cutting parameters of fully conjugated tooth surface can be derived as follows:

$$
\left\{\begin{array}{c}
E_{x 2}=\sqrt{R_{p}^{2}+r_{0}^{2}-2 R_{p} r_{0} \cos \left(90-\beta_{p}+\delta_{0}\right)} \\
q_{2}=\arcsin \left[r_{0} \sin \left(90-\beta_{p}+\delta_{0}\right) / E_{x 2}\right]+\left(\beta_{m 2}-\beta_{p}\right) \\
E_{m 2}=\sin \left(\beta_{m 2}-\beta_{p}\right)\left(r_{m 2} \cos 90^{\circ}+R_{p} \cos \delta_{2}\right) / \sin \left(90^{\circ}+\delta_{M 2}\right) \\
X_{b 2}=|A B|=\left[R_{m 2}-R_{p} \cos \left(\beta_{m 2}-\beta_{p}\right)\right] \tan \delta_{M 2} \\
X_{g 2}=Z_{r 2}-|A B| / \sin \delta_{M 2}=Z_{r 2}-\left[R_{m 2}-R_{p} \cos \left(\beta_{m 2}-\beta_{p}\right)\right] / \cos \delta_{M 2} \\
m_{p 2}=z_{p 2} / z_{2} \\
i_{p 2}=z_{0} / z_{p 2} \\
\delta_{M 2}=\delta_{2}
\end{array}\right.
$$

\section{Double crowned of tooth surface \\ 3.1 Modification of tooth length direction}

In order to make the fully conjugated tooth surface mismatch in the direction of tooth length, the curvature of tooth length can be corrected by changing the radius of cutter blade edge, thus the crown mismatch is formed in the direction of tooth length (Nie et al., 2017). Figure 4 shows the principle of correcting the curvature of tooth length direction by using the radius of cutter head. As seen in Fig. 4, $O_{e}$ is the center of cutter head of pinion outer cutter and $O_{i}$ is the center of cutter head of gear inner cutter. When the radius of the outer cutter of pinion is larger than that of the inner cutter of gear, there is only one common tangent between the generating surface formed by the outer cutter of the pinion and the generating surface formed by the inner cutter of the gear. In the direction of tooth length of arbitrary cross section, the curvature of tooth trace of meshing tooth surface is different, so the two conjugate tooth surfaces form point conjugation at point $M$. 


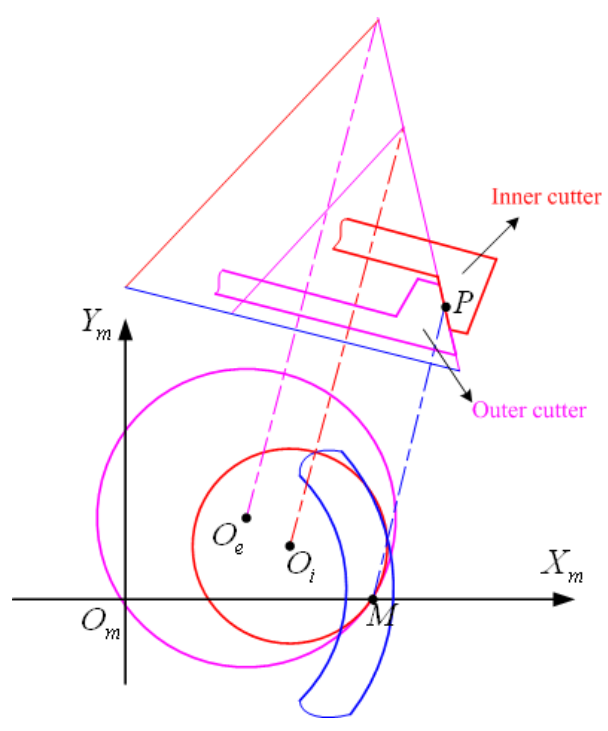

Fig. 4 The principle of radius modification curvature of tooth length

For the cutter head of cycloidal bevel gear, there has an important parameter $F$ which is called the convexity value of cutter head, and the parameter is supplied by the tool manufacturer.The convexity value $F$ is one constant which is used to determine the intersection angle between the inner blade edge and outer blade edge. For example,for Oerlikon FN cutter head,the convexity value $F$ is 24 degree. Figure 5 shows the relationship between the theoretical intersection angle and the actual intersection angle. For the theoretical cutter head, the theoretical intersection angle $\tau_{w 0}$ between the inner blade edge and outer blade edge is equal to $180^{\circ} / z_{0}$. When the convexity value $F$ is given, the actual intersection angle $\tau_{w}$ between the inner blade edge and outer blade edge will no longer be equal to $\tau_{w 0}$, and their differential value is $F / z_{0}$.

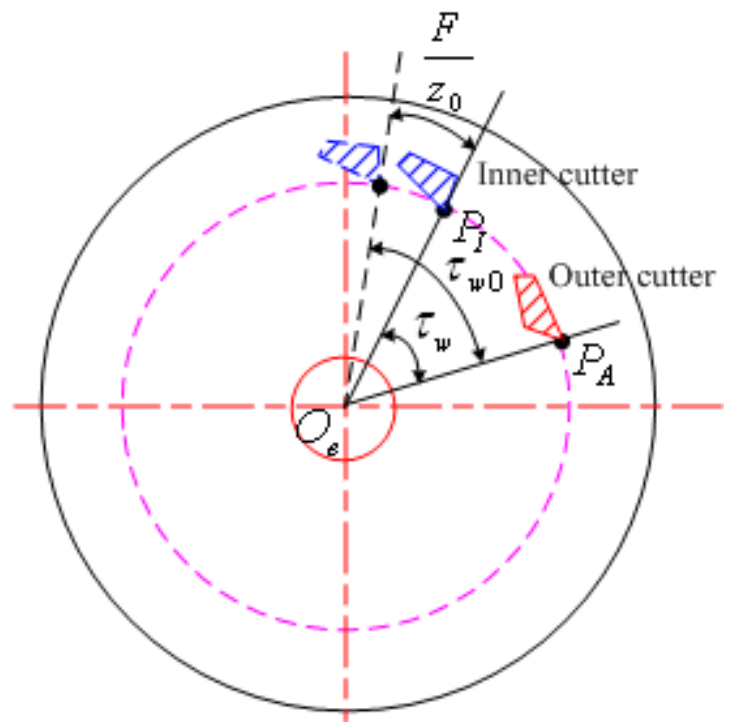

Fig. 5 The relationship between theoretical and actual intersection angle

To ensure the tooth thickness, the radius of cutter blade edge needs to be corrected accordingly. When the convexity value $F$ of the cutter head is given, the actual intersection angle between the inner blade edge and outer blade edge is $(180-F) / z_{0}$. Compared with the theoretical value, the intersection angle between the inner blade edge and outer blade edge changes by $\Delta \tau=-F / z_{0}$, which will cause the change of the tooth thickness angle of generating gear, with a change of $\Delta \varphi_{p}=z_{0} \Delta \tau / z_{p}$. The change of tooth thickness angle will cause the change of slot width, which is $\Delta s_{n p}=\pi r_{p} \Delta \varphi_{p} \cos \beta_{p} / 180$. By dividing the variation of the slot width into the radius of cutter blade edge, the modification of the radius of cutter blade edge is $\Delta r_{b}=\Delta s_{n \nu} / 2$.

The tangential modification factor $x_{t 1}$ and the backlash $j_{n}$ of the gear are introduced, and the tangential radius 
of the modified cutter blade edge can be calculated according to the following formula:

$$
\left\{\begin{array}{l}
r_{b I 1}=r_{b}-\Delta r_{b}+0.5 m_{n} x_{t 1}-0.25 j_{n} \\
r_{b A 1}=r_{b}+\Delta r_{b}-0.5 m_{n} x_{t 1}+0.25 j_{n} \\
r_{b I 2}=r_{b}-\Delta r_{b}-0.5 m_{n} x_{t 1}-0.25 j_{n} \\
r_{b A 2}=r_{b}+\Delta r_{b}+0.5 m_{n} x_{t 1}+0.25 j_{n}
\end{array}\right.
$$

Formula (2) shows that the tangential radius of the outer cutter of pinion is larger than that of the inner cutter of the gear, so the curvature of the concave side of pinion is smaller than that of the convex side of gear. Both of them form a crown shape in the direction of tooth length, resulting in mismatch. Similarly, the tangential radius of the outer cutter of gear is larger than that of the inner cutter of the pinion, so the concave curvature of gear is smaller than that of the convex side of pinion. Both of them also form a crown shape in the direction of tooth length and cause mismatch.

\subsection{Tooth profile modification}

The tooth profile modification can be achieved by modifying the shape of cutter blade edge. Figure 6(a) shows the cutter blade edge shape which is viewed along $A$ direction vertical to the plane $H$ (seen in Fig.1).The traditional cutter blade edge shape is straight line,here the cutter blade edge is modified into the circular arc shape, so the modification of the tooth profile direction can be realized by controlling the curvature radius of arc blade edge. When the straight blade edge is modified to the arc blade edge, the tooth surface in the tooth profile direction is modified to the crown shape, as shown in Fig.6(b).The thinner broken curve is the crown tooth surface processed by arc blade edge, and the thicker solid curve is the tooth surface formed by straight blade edge. As seen from Fig. 6(b), tooth surface mismatch occurs along the tooth profile direction, and the meshing tooth surface becomes the local conjugate contact.

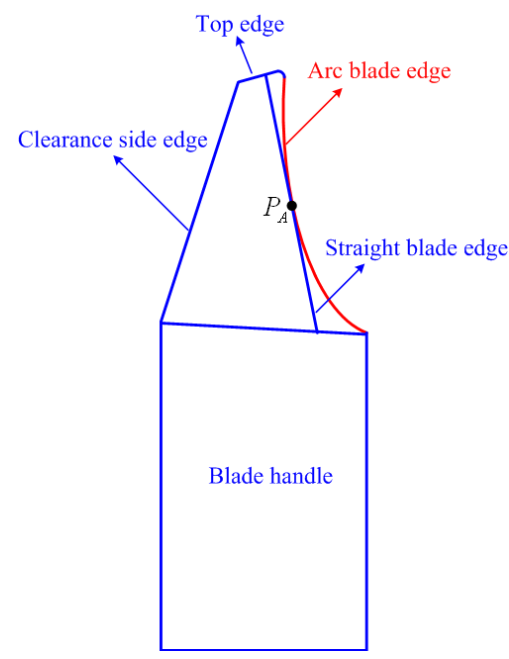

(a) Shape of cutter blade edge

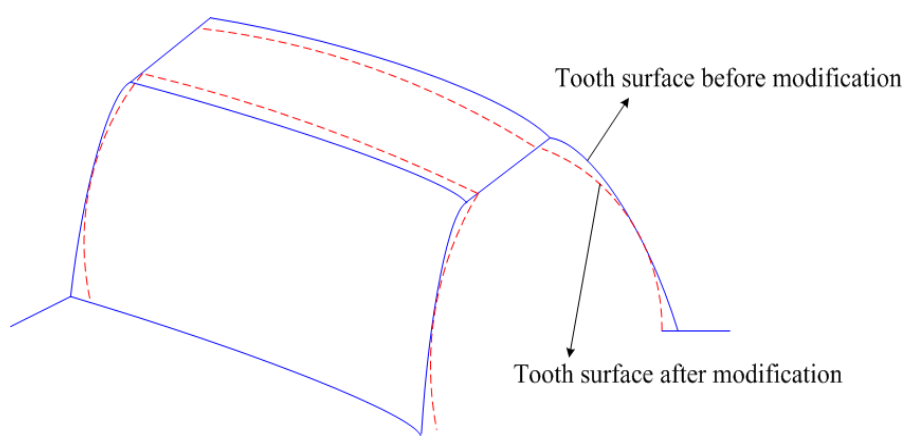

(b) Tooth profile modification

Fig. 6 Crowned modification in the tooth profile direction

\section{Derivation of tooth surface equation 4.1 Mathematical model of cutter head}

Taking the left hand pinion for example, Figure 7 shows the mathematical model of pinion cutter head of cycloidal bevel gear. The coordinate systems in Fig.7(a) is built in the cutter pitch point plane $T$. The nominal pitch point of cutter head is point $P_{0}, r_{0}=\left|O_{e} P_{0}\right|$ is the nominal radius of cutter head. After the radius of cutter head is corrected, the outer cutter pitch point becomes point $P_{A}$, and the inner cutter pitch point becomes point $P_{I}$. The distance between the inner and outer cutter pitch points and point $P_{0}$ is called the tangential radius correction value. $\tau_{w}$ is the intersection angle between the inner blade edge and outer blade edge, $\delta_{0 I}$ and $\delta_{04}$ are the direction angles 
of the inner blade edge and the outer blade edge, respectively. The coordinate system $S_{e}\left(X_{e}, Y_{e}, Z_{e}\right)$ is fixed with the cutter head, and rotates with the cutter head in processing. The coordinate axis $X_{e}$ passes through the straight line $O_{e} P_{0}$. The coordinate system $S_{e 2}\left(X_{e 2}, Y_{e 2}, Z_{e 2}\right)$ is an auxiliary coordinate system. The origin of the coordinate system coincides with the pitch point $P_{0}$. The coordinate axis $X_{e 2}$ coincides with the projection line of cutting edge on the transverse plane of the cutter head. The coordinate system $S_{e 1}\left(X_{e 1}, Y_{e 1}, Z_{e 1}\right)$ is fixed with the cutter blade edge, the origin of the coordinate system coincides with the pitch point $P_{A}$ of the outer cutter, the coordinate axis $X_{e 1}$ coincides with the coordinate axis $X_{e 2}$, and the coordinate axis $Z_{e 1}$ is parallel to the axis of the cutter head.

The coordinate system $S_{e 2}\left(X_{e 2}, Y_{e 2}, Z_{e 2}\right)$ and $S_{e 1}\left(X_{e 1}, Y_{e 1}, Z_{e 1}\right)$ are built in the plane $H$, and the plane $H$ is vertical to plane $T$, and the shape of cutter blade edge located in plane $H$ is shown in Fig. 7 (b). $\Delta r_{b I}=\left|P_{0} P_{I}\right|$ is the tangential radius correction value of inner cutter, $\Delta r_{b A}=\left|P_{0} P_{A}\right|$ is the tangential radius correction value of outer cutter. $\alpha_{I}$ is the profile angle of the inner blade edge, take $\alpha_{I}$ as the positive value. $\alpha_{A}$ is the profile angle of the outer blade edge, $\alpha_{A}$ is the negative value. $G_{A}$ and $G_{I}$ are arbitrary points on the outer blade edge and the inner blade edge, respectively. The corresponding parameters of are $u_{A}=\overline{P_{A} G_{A}}$ and $u_{I}=\overline{P_{I} G_{I}}$, respectively. It is stipulated that the positive value should be taken. $R_{H A}$ is the radius of curvature of the outer arc' blade edge and $R_{H I}$ is the radius of curvature of the inner arc blade edge.
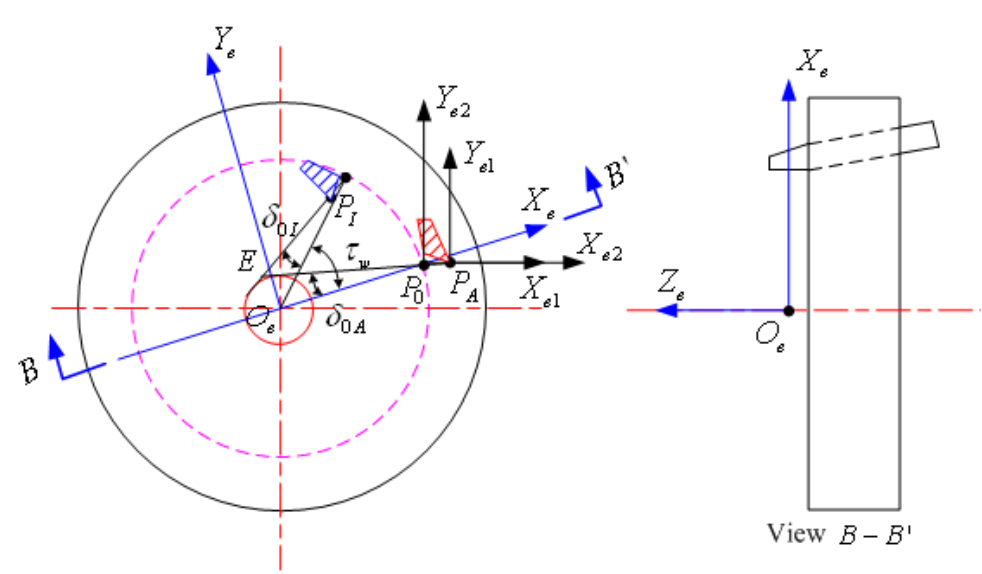

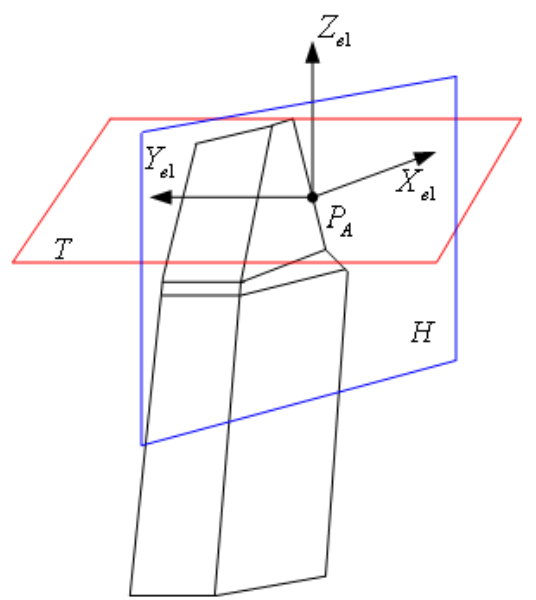

(a) Coordinate system of cutter head

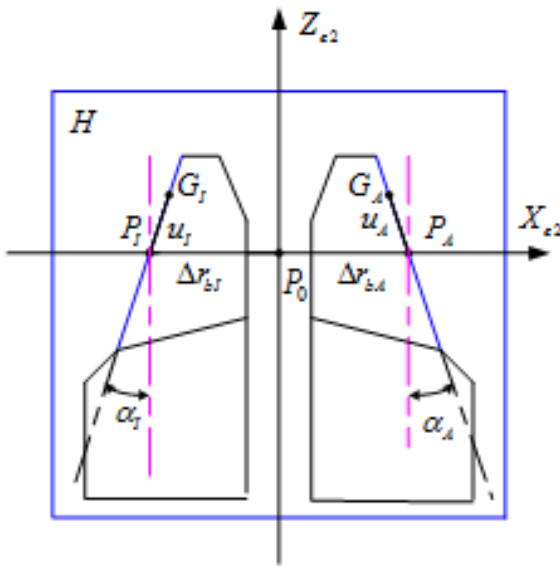

Straight blade edge

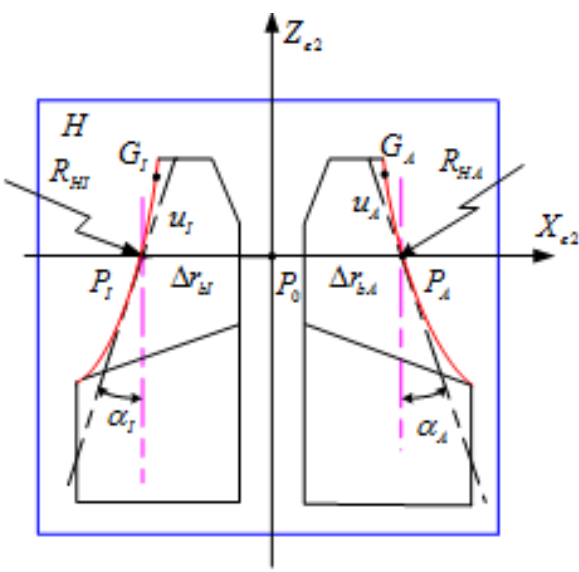

Arc blade edge

(b) Coordinate system of cutter blade edge

Fig. 7 Mathematical model of cutter head

From the geometric relationship in Fig.7(b), the vector equation of the cuter blade edge can be obtained directly in the coordinate system $S_{e 2}\left(X_{e 2}, Y_{e 2}, Z_{e 2}\right)$ :

For straight blade edge: 


$$
\boldsymbol{r}_{e 2}=\left[\begin{array}{llll}
\Delta r_{b k}+u_{k} \sin \alpha_{k} & 0 & u_{k} \cos \alpha_{k} & 1
\end{array}\right]^{T}
$$

For arc blade edge:

$$
\boldsymbol{r}_{e 2}=\left(\begin{array}{c}
R_{H k}\left(\left(1-\cos \left(u_{k} / R_{H k}\right)\right) \cos \alpha_{k}-\sin \left(u_{k} / R_{H k}\right) \sin \alpha_{k}\right)+\Delta r_{b k} \\
0 \\
R_{H k}\left(\left(1-\cos \left(u_{k} / R_{H k}\right)\right) \sin \alpha_{k}+\sin \left(u_{k} / R_{H k}\right)\right) \cos \alpha_{k} \\
1
\end{array}\right)
$$

In the formulas (3) and (4), the subscripts $k=A, I$ correspond to the outer cutter and the inner cutter, respectively.

According to the coordinate system relationship in Fig.7(a), the equation $\boldsymbol{r}_{e}=M_{A I} M_{e e 2} \boldsymbol{r}_{e 2}$ of the cutter blade edge in the cutter head coordinate system $S_{e}\left(X_{e}, Y_{e}, Z_{e}\right)$ can be obtained by corresponding coordinate transformation, of which $M_{e e 2}$ and $M_{A I}$ are coordinate system transformation matrices.

\subsection{Mathematical model of generating gear}

Figure 8 shows the mathematical model of generating gear in the process of pinion cutting. Figure 8 (a) shows the position relationship diagram of the cutter head after tilt. $S_{\mathrm{e}}\left(X_{e}, Y_{e}, Z_{e}\right)$ is the cutter head coordinate system, which is fixed with the cutter head, and $S_{\mathrm{e} 0}\left(X_{e 0}, Y_{e 0}, Z_{e 0}\right)$ is the auxiliary coordinate system, which is defined as the original position of the cutter head. When the tilt method is used, the tilt angle of the cutter spindle $Z_{e}$ relative to the original position axis $Z_{e 0}$ is $\chi_{1}$. In the process of machining, the cutter head first rotates around coordinate axis $Y_{e 0}$ with a tilt angle of $\chi_{1}$, and the coordinate system changes to position 1 . Then it rotates around the cutter head axis $Z_{e}$ clockwise with an angle of $\varphi_{1}$ (the counterclockwise rotation angle is $-\varphi_{1}$ in the Fig.7(a)), and the coordinate system changes to position 2 .

Figure 8 (b) shows the motion relationship between the cutter head and the generating gear. After the cutter head rotates clockwise, the axis of the generating gear rotates clockwise at an angle of $\varphi_{p}$. From the motion relationship between the cutter head and the generating gear, $\varphi_{p}=i_{p 0} \varphi_{1}$ can be obtained, and $i_{p 0}$ is the speed ratio of tooth dividing. The original position is $\varphi_{p}=0$, and the generating gear coordinate system $S_{p}\left(X_{p}, Y_{p}, Z_{p}\right)$ coincides with the starting coordinate system $S_{p 0}\left(X_{p 0}, Y_{p 0}, Z_{p 0}\right) \cdot E_{x 1}$ is the radial setting of pinion, $q_{1}$ is the basic cradle angle of pinion, $J_{1}$ is the basic swivel angle of pinion, and $S_{c}\left(X_{c}, Y_{c}, Z_{c}\right)$ is the auxiliary coordinate system.
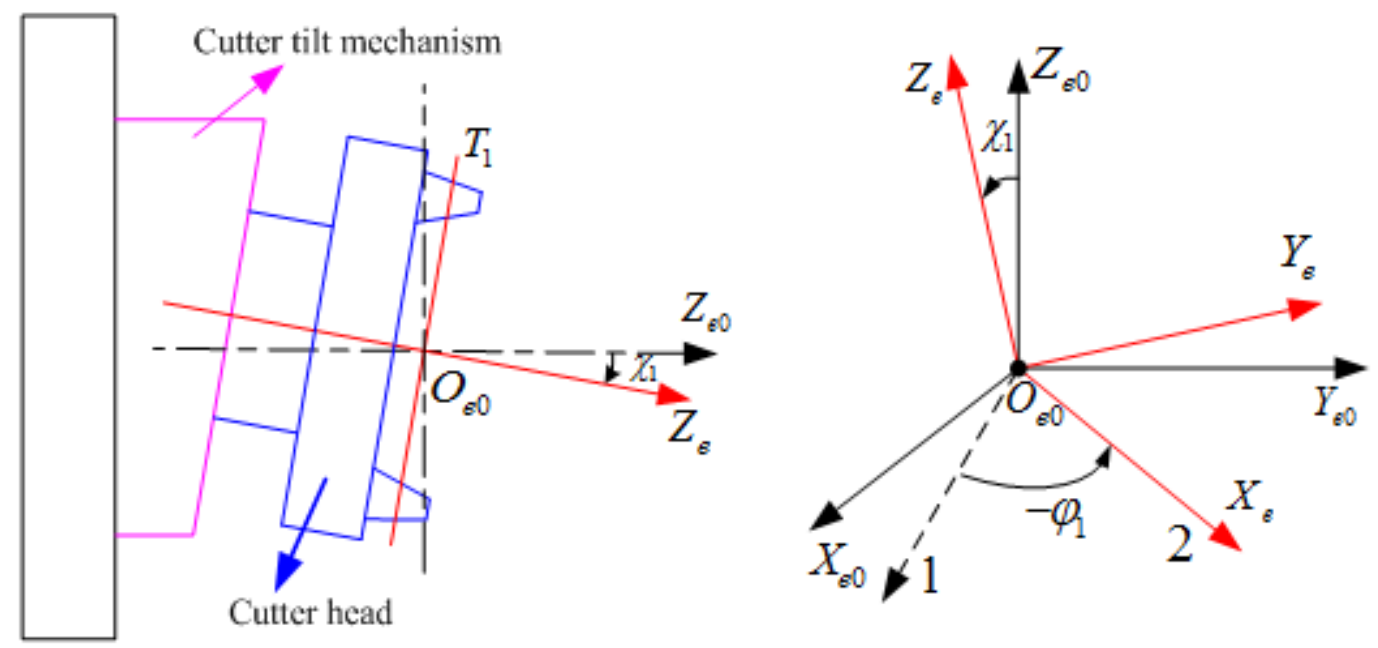

(a) Cutter head position after tilt 


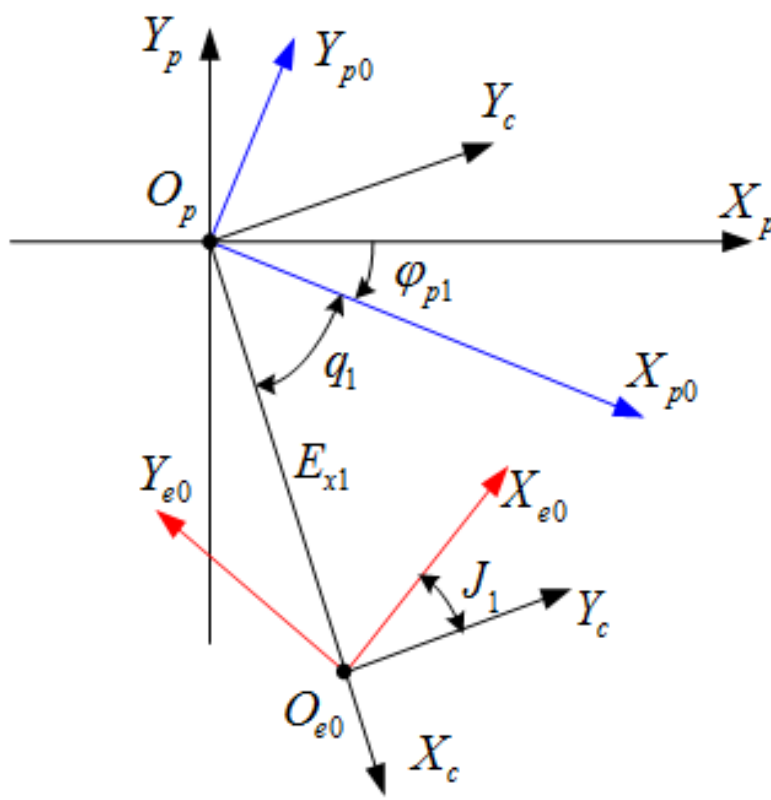

(b) The relationship between cutter head and generating gear

Fig. 8 Mathematical model of generating gear for pinion

Combining the relationship between coordinate systems in Fig.8 (a) and Fig.8 (b), through a series of coordinate transformation, we can get the tooth surface equation and the unit normal vector of the generating gear are $\boldsymbol{r}_{p}\left(u_{1}, \varphi_{1}\right)=M_{p p 0} M_{p 0 c} M_{c e 0} M_{e 0 e} \boldsymbol{r}_{e}\left(u_{1}, \varphi_{1}\right)$ and $\boldsymbol{n}_{p}=\left(\frac{\partial \boldsymbol{r}_{p}}{\partial u_{1}} \times \frac{\partial \boldsymbol{r}_{p}}{\partial \varphi_{1}}\right) /\left|\frac{\partial \boldsymbol{r}_{p}}{\partial u_{1}} \times \frac{\partial \boldsymbol{r}_{p}}{\partial \varphi_{1}}\right|$, respectively.

\subsection{Mathematical model of cutting}

Figure 9 shows the mathematical model of pinion cutting. $S_{m}\left(X_{m}, Y_{m}, Z_{m}\right)$ is the coordinate system of machine tool, which is built in the machine plane $T$ and is fixed with the machine tool. $S_{p}\left(X_{p}, Y_{p}, Z_{p}\right)$ is the coordinate system of the generating gear, which is fixed with the cradle, and rotates with the cradle at an angle of $\phi_{g 1}$ during the development process. The horizontal plane of the machine tool passes through the axis of the gear blank and is perpendicular to the machine plane $T . S_{n}\left(X_{n}, Y_{n}, Z_{n}\right)$ and $S_{a}\left(X_{a}, Y_{a}, Z_{a}\right)$ are auxiliary coordinate systems, and $S_{n}$ is parallel to $S_{m}$. The coordinate axis $X_{a}$ coincides with the axis of the gear blank. The coordinate system $S_{1}\left(X_{1}, Y_{1}, Z_{1}\right)$ is fixed with the gear blank, and the rotation angle around the gear axis is $\phi_{w 1}$ in the process of generating. In the initial position, coordinate system $S_{1}$ coincides with $S_{a} . O_{1}$ is the crossing point of the gear blank design, and point $A$ is the vertical foot of the common vertical line between the axis of the generating gear and the axis of the gear blank in the cutting process. $X_{g 1}$ is the increment of machine center to back of pinion, $X_{b 1}$ is the sliding base setting of pinion, $\delta_{M 1}$ is the machine root angle of pinion, $E_{m 1}$ is the vertical offset of pinion, $\omega_{p 1}$ is the angular velocity of generating gear, $\omega_{1}$ is the angular velocity of pinion.

According to coordinate relationship in Fig.9, after a series of coordinate transformation, the pinion tooth surface equation $\boldsymbol{r}_{1}\left(u_{1}, \varphi_{1}, \phi_{g 1}\right)=M_{1 a} M_{a n} M_{n m} M_{m p} \boldsymbol{r}_{p}\left(u_{1}, \varphi_{1}\right)$ and the unit normal vector $\boldsymbol{n}_{1}\left(u_{1}, \varphi_{1}, \phi_{g 1}\right)=L_{1 a} L_{a n} L_{n m} L_{m p} \boldsymbol{n}_{p}\left(u_{1}, \varphi_{1}\right)$ can be derived.

From the meshing equation $\Phi=f\left(u_{1}, \varphi_{1}, \phi_{g 1}\right)=\boldsymbol{n}_{m} \bullet \boldsymbol{v}_{m}^{(p 1)}=0, \phi_{g 1}=\phi_{g 1}\left(u_{1}, \varphi_{1}\right) \quad$ can be deduced and substituted into the tooth surface equation of the gear. $\phi_{g 1}$ can be eliminated. Finally, the pinion tooth surface equation $\boldsymbol{r}_{1}\left(u_{1}, \varphi_{1}\right)$ and the unit normal vector $\boldsymbol{n}_{1}\left(u_{1}, \varphi_{1}\right)$ can be obtained. 


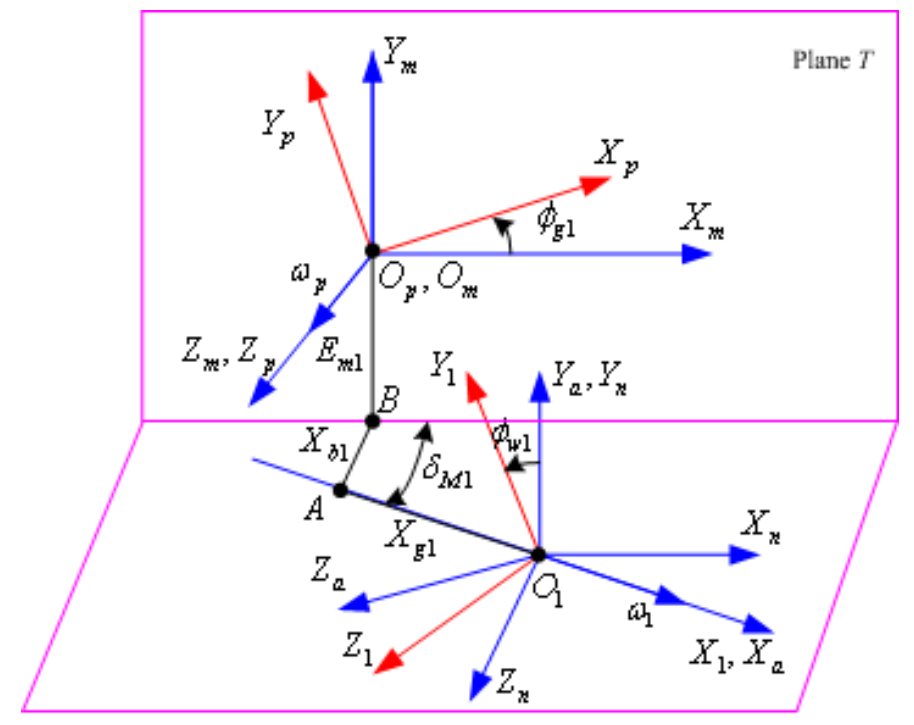

Fig. 9 Mathematical model of pinion cutting

\section{Mathematical model of tooth surface mismatch}

Figure 10 shows the mathematical model of tooth surface meshing, $S_{1}\left(X_{1}, Y_{1}, Z_{1}\right)$ and $S_{2}\left(X_{2}, Y_{2}, Z_{2}\right)$ are workpiece coordinate systems which are fixed with pinion and gear, respectively. During the meshing process, they rotate with gear, and the revolving angle are $\phi_{1}$ and $\phi_{2}$, respectively. $S_{a}\left(X_{\mathrm{a}}, Y_{\mathrm{a}}, Z_{\mathrm{a}}\right)$ is a fixture mounting coordinate system, $S_{\mathrm{d}}\left(X_{\mathrm{d}}, Y_{\mathrm{d}}, Z_{\mathrm{d}}\right)$ and $S_{\mathrm{b}}\left(X_{\mathrm{b}}, Y_{\mathrm{b}}, Z_{\mathrm{b}}\right)$ are auxiliary coordinate systems. $\Delta E$ is vertical variation between the axis of gear pair, $\Delta H_{1}$ and $\Delta H_{2}$ are the variation of axial position of pinion and gear, respectively, and the angle between axis is $\Sigma=90^{\circ}$.

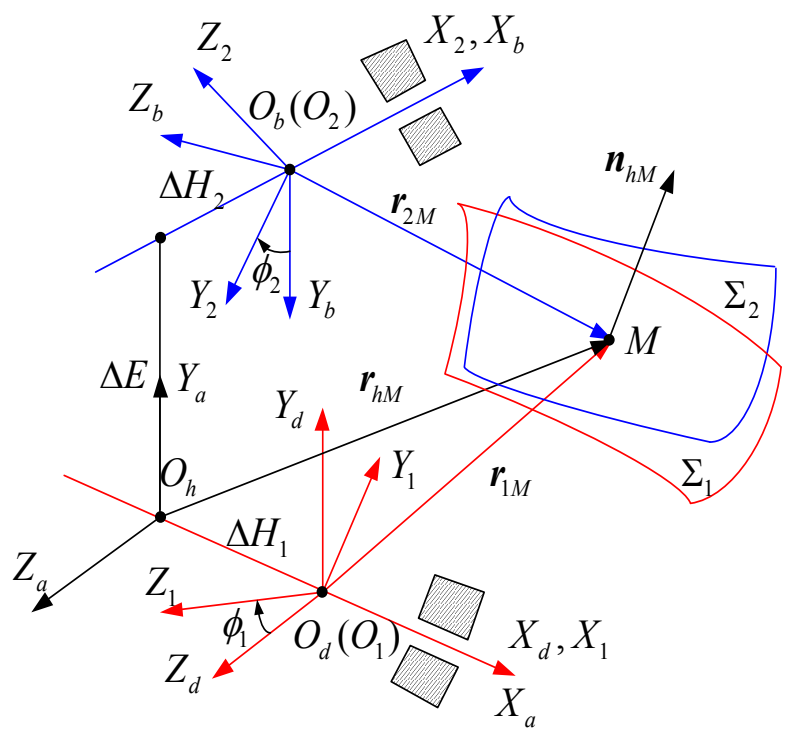

Fig. 10 Gear meshing coordinate systems

From Section 4, we can get the vector equation $\boldsymbol{r}_{2}\left(u_{2}, \varphi_{2}\right)$ and unit normal vector $\boldsymbol{n}_{2}\left(u_{2}, \varphi_{2}\right)$ of gear tooth surface, and transform the equation of gear tooth surface and unit normal vector into coordinate system $S_{a}$. It can be obtained that:

$$
\left\{\begin{array}{l}
\boldsymbol{r}_{a}\left(u_{2}, \varphi_{2}, \phi_{2}\right)=M_{a b} M_{b 2} \boldsymbol{r}_{2}\left(u_{2}, \varphi_{2}\right) \\
\boldsymbol{n}_{a}\left(u_{2}, \varphi_{2}, \phi_{2}\right)=L_{a b} L_{b 2} \boldsymbol{n}_{2}\left(u_{2}, \varphi_{2}\right)
\end{array}\right.
$$


In the meshing process, the meshing equation of gear and pinion is established at the mesh point, which is expressed in coordinate system $S_{a}$ as follows:

$$
\Phi=f\left(u_{2}, \varphi_{2}, \phi_{2}\right)=\boldsymbol{n}_{a} \bullet \boldsymbol{v}_{a}^{(21)}=0
$$

In formula (6), $v_{a}^{(21)}$ is the relative speed between the gear and the pinion. When the tooth surface of pinion is fully conjugated with that of gear, $\phi_{2} / \phi_{1}=z_{1} / z_{2}=m_{21}$ is satisfied in the meshing process, of which $z_{1}$ is the tooth number of pinion and $z_{2}$ is the tooth number of gear.

Formula (6) can be used to get $\phi_{2}=\phi_{2}\left(u_{2}, \varphi_{2}\right)$, and substituting it into formula (5) can eliminate variable $\phi_{2}$ to get equation $\boldsymbol{r}_{a}\left(u_{2}, \varphi_{2}\right)$ and unit normal vector $\boldsymbol{n}_{a}\left(u_{2}, \varphi_{2}\right)$ of gear in coordinate system $S_{a}$.Converting it to the coordinate system $S_{1}$ of pinion, we can get

$$
\left\{\begin{array}{l}
\boldsymbol{r}_{1}\left(u_{2}, \varphi_{2}\right)=M_{1 d} M_{d a} \boldsymbol{r}_{a}\left(u_{2}, \varphi_{2}\right) \\
\boldsymbol{n}_{1}\left(u_{2}, \varphi_{2}\right)=L_{1 d} L_{d a} \boldsymbol{n}_{a}\left(u_{2}, \varphi_{2}\right)
\end{array}\right.
$$

Formula (7) can be used to solve the tooth surface of pinion, which is fully conjugated with the tooth surface of gear. The equation of tooth surface is $\boldsymbol{r}_{1}\left(u_{2}, \varphi_{2}\right)$ and the unit normal vector is $\boldsymbol{n}_{1}\left(u_{2}, \varphi_{2}\right)$. The fully conjugated tooth surface of pinion is defined as the base tooth surface of pinion and expressed by $\boldsymbol{r}_{1}$. The tooth surface of pinion derived from Section 4 is defined as the actual tooth surface of pinion, which is expressed by $\boldsymbol{r}_{1}^{\prime}$. According to the vector relationship between the two tooth surfaces, the deviation between the actual tooth surface of pinion and the base tooth surface of pinion can be expressed as $\Delta \varepsilon=\left(\boldsymbol{r}_{1}^{\prime}-\boldsymbol{r}_{1}\right) \bullet \boldsymbol{n}_{1}$. The topography graph of tooth surface deviation constructed by these tooth surface deviations reflects the mismatch relationship between the surface of the pinion and the gear, which is called the tooth surface Ease off topography graph (Shih et al., 2007; Kolivand M., 2009; Alessio., 2013; Nie et al., 2017).

\section{Tooth surface mismatch modification}

\subsection{Calculation of mismatch coefficient of tooth surface}

Because the tooth mismatch is composed of the tooth surface deviation of all grid nodes between the actual tooth surface of pinion and the base tooth surface of pinion, it is essentially a kind of tooth surface deviation. Generally speaking, the mismatch deviation of tooth surface can be approximated as by the second-order surface polynomial (Nie et al., 2017) (as shown in Fig.11):

$$
\Delta \varepsilon=a_{\beta} X+a_{\alpha} Y+a_{L} X^{2}+a_{H} Y^{2}+a_{v} X Y
$$

In formula $(8),(X, Y)$ is the coordinates of grid nodes along the direction of tooth length and tooth profile, with the mean point of tooth surface as the origin. $a_{\beta}$ - the error coefficient of spiral angle, $a_{\alpha}$ - the error coefficient of pressure angle, $a_{L}$ - the crown coefficient of tooth length, $a_{H}$ - the crown coefficient of tooth profile, $a_{v}$ - the torsion coefficient of tooth surface. These five coefficients reflect the mismatch degree of the tooth surface in five directions, which is called the mismatch coefficient of tooth surface.

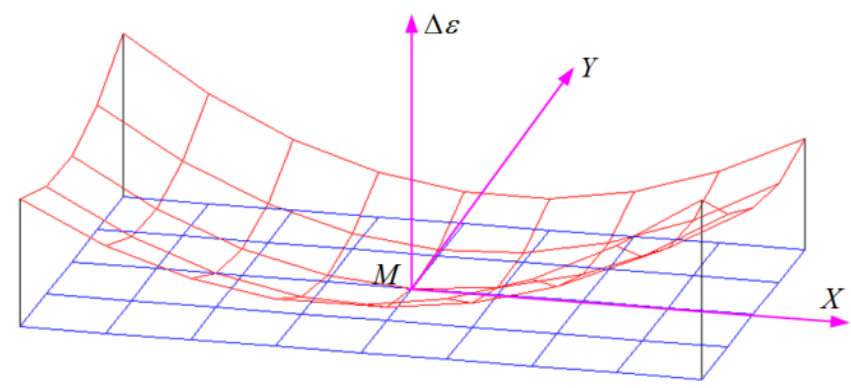

Fig. 11 Mismatch topology of tooth surface

If the tooth surface deviation of all grid nodes on the tooth surface is known, then the tooth surface mismatch deviation can be expressed as the following matrix form by expanding formula (8): 


$$
\left(\begin{array}{c}
\Delta \varepsilon_{1} \\
\Delta \varepsilon_{2} \\
\Delta \varepsilon_{3} \\
\ldots \\
\Delta \varepsilon_{m \times n}
\end{array}\right)=\left(\begin{array}{ccccc}
X_{1} & Y_{1} & X_{1}^{2} & Y_{1}^{2} & X_{1} Y_{1} \\
X_{2} & Y_{2} & X_{2}^{2} & Y_{2}^{2} & X_{2} Y_{2} \\
X_{3} & Y_{3} & X_{3}^{2} & Y_{3}^{2} & X_{3} Y_{3} \\
\ldots & \ldots & \ldots & \ldots & \ldots \\
X_{m \times n} & Y_{m \times n} & X_{m \times n}^{2} & Y_{m \times n}^{2} & X_{m \times n} Y_{m \times n}
\end{array}\right)\left(\begin{array}{c}
a_{\beta} \\
a_{\alpha} \\
a_{L} \\
a_{H} \\
a_{v}
\end{array}\right)
$$

In formula (9), $m$ is the number of grid rows on the tooth surface and $n$ is the number of grid columns on the tooth surface. Formula (9) is a set of overdetermined linear equations for solving the mismatch coefficient $\left(a_{\beta}, a_{\alpha}, a_{L}, a_{H}, a_{v}\right)$ of tooth surface. By using the least square method, the mismatch coefficients of tooth surface in five directions can be obtained.

\subsection{Control of tooth surface mismatch}

At present, the mismatch relationship between pinion and gear has been established. Because the mismatch relationship reflects the meshing situation between the two tooth surfaces, in order to change the meshing performance of the current tooth surface, it can be achieved by controlling the mismatch relationship between the tooth surfaces. The calculation steps are as follows: the current mismatch coefficients of tooth surface are calculated firstly,and the current tooth mismatch coefficients are controlled by modifying the tooth mismatch relationship,then the deviations between the current tooth surface of pinion and the target tooth surface of gear after controlling are solved,finally by eliminating the tooth surface deviations, the processing parameters of pinion can be obtained. Therefore, the current tooth surface of pinion can be corrected. Figure 12 shows the deviations relationship between the current tooth surface and target tooth surface of pinion.

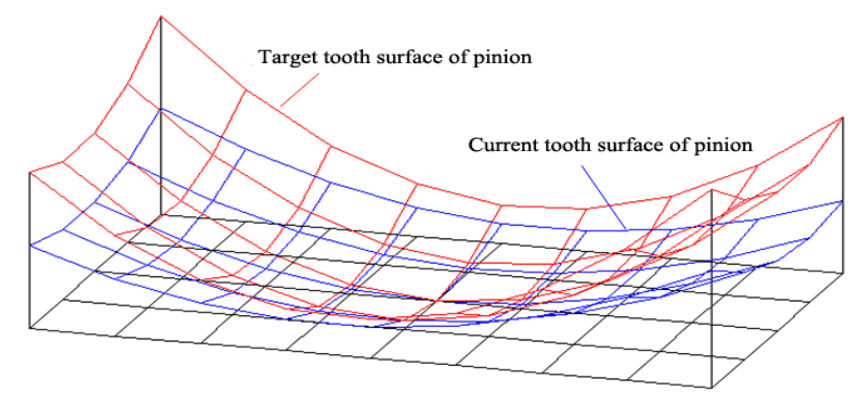

Fig. 12 The deviations relationship between the current tooth surface and target tooth surface of pinion

The mismatch of grid nodes on the tooth surface in the current ease off topology is represented by $\Delta \varepsilon_{i}^{\prime}(i=1 \sim m \times n)$, and the mismatch of grid nodes on the tooth surface in the target ease off topology is represented by $\Delta \varepsilon_{i}(i=1 \sim m \times n)$. Thus, the deviations $\Delta \delta_{i}=\Delta \varepsilon_{i}-\Delta \varepsilon_{i}^{\prime}$ of grid nodes on the current tooth surface and the target tooth surface of the pinion can be obtained.

As Nie proposed (2018), the mathematical equation between tooth surface deviations $\left\{\Delta \delta_{i}\right\}$ and the processing parameters modification $\left\{\Delta \psi_{q}\right\}$ can be established as follows:

$$
\left\{\Delta \delta_{i}\right\}=\left[S_{i q}\right]\left\{\Delta \psi_{q}\right\} \quad(i=1 \sim m \times n, q=1 \sim k)
$$

In formula (10), $\left[S_{i q}\right]$ is the error sensitivity matrix of processing parameters and $k$ is the number of corrected processing parameters. Because formula (10) is an overdetermined equation, in order to avoid the occurrence of ill-conditioned matrix, the least square singular value decomposition (SVD) algorithm (Li et al., 2008; Tang et al., 2012; Shih et al., 2008) can be used to solve it.

$$
\left\{\Delta \psi_{q}\right\}=\left(\left\lceil S_{i q}\right\rceil^{T}\left\lceil S_{i q}\right\rceil\right)^{-1}\left\lceil S_{i q}\right\rceil^{T}\left\{\Delta \delta_{i}\right\}
$$

\section{Example analysis}

In order to verify the correctness of the tooth surface modification method proposed in this paper, a pair of 
cycloidal bevel gear is taken as an example to show the complete mismatch modification process from fully conjugated tooth surface to locally conjugated tooth surface. Table 1 gives the geometric parameters of the gear pair and Table 2 gives the original cutting parameters, which are obtained from the formulas in Section 2.2 above.

Table 1 Geometric parameters of gear blank

\begin{tabular}{l|c|c}
\hline \hline Name & Pinion & Gear \\
\hline Teeth number & 21 & 28 \\
Spiral hand & LH & RH \\
Shaft angle $/\left(^{\circ}\right)$ & 90 & 90 \\
Offset $/(\mathrm{mm})$ & 0 & 0 \\
Normal modulus of reference point $/(\mathrm{mm})$ & 7.1886 & 7.188 \\
Mean spiral angle $/\left(^{\circ}\right)$ & 33 & 33 \\
Pressure angle $/\left(^{\circ}\right)$ & 22.5 & 22.5 \\
Addendum $/(\mathrm{mm})$ & 7.1886 & 7.1886 \\
Whole depth $/(\mathrm{mm})$ & 16.1743 & 16.1743 \\
Face angle $/\left(^{\circ}\right)$ & 36.87 & 53.13 \\
Pitch angle $/\left(^{\circ}\right)$ & 36.87 & 53.13 \\
Root angle $/\left(^{\circ}\right)$ & 36.87 & 53.13 \\
Out cone distance $/(\mathrm{mm})$ & 175 & 175 \\
Face width $/(\mathrm{mm})$ & 50 & 50 \\
\hline
\end{tabular}

Table 2 Processing parameters of original gear cutting

\begin{tabular}{l|c|c}
\hline \hline Name & Pinion & Gear \\
\hline Group number of cutter & 5 & 5 \\
Nominal radius of cutter head $/(\mathrm{mm})$ & 90 & 90 \\
Tilt angle $/\left(^{\circ}\right)$ & 0 & 0 \\
Swivel angle $\left./{ }^{\circ}\right)$ & 14.0944 & 165.9056 \\
Radial setting $/(\mathrm{mm})$ & 143.9158 & 143.9158 \\
Basic cradle angle/ $\left(^{\circ}\right)$ & 35.5714 & 35.5714 \\
Vertical offset $/(\mathrm{mm})$ & 0 & 0 \\
Increment of machine center to back $/(\mathrm{mm})$ & 0 & 0 \\
Sliding base feed setting/( $\mathrm{mm})$ & 0 & 0 \\
Machine root angle $/\left(^{\circ}\right)$ & 36.8689 & 53.1311 \\
Roll ratio & 1.666667 & 1.25 \\
\hline
\end{tabular}

The tooth mismatch meshing simulation of the original cutting parameters in Tab.2 can obtain the ease off topology and the tooth contact area, as shown in Fig.13. Fig.13(a),(b)shows the ease off for drive side and ease off for coast side,respectively, here, the blue grid represents the pinion tooth surface,and the black grid represents the gear tooth surface. From Fig.13(a),it can be seen that the ease off values between the pinion concave and gear convex are $0.0012 \mu \mathrm{m}$ at the top of heel position, $-0.001 \mu \mathrm{m}$ at the root of heel position, $-0.001 \mu \mathrm{m}$ at the top of toe position, $0.001 \mu \mathrm{m}$ at the root of toe position, respectively, and the ease off values are approximate to 0 in the region of whole tooth surface. The so small ease off values show that the pinion concave and gear convex are fully conjugated tooth surface.Similarly, From Fig.13(b),it can be seen that the ease off values between the pinion convex and gear concave are $0.001 \mu \mathrm{m}$ at the top of heel position, $-0.001 \mu \mathrm{m}$ at the root of heel position, $0.0011 \mu \mathrm{m}$ at the top of toe position, $0.0011 \mu \mathrm{m}$ at the root of toe position,respectively, and the ease off values are approximate to 0 in the region of whole tooth surface. The so small ease off values also show that the pinion convex and gear concave are fully conjugated tooth surface.From Fig.13(c),(d), it can be seen that the tooth contact areas are all over the whole tooth surface, so the ease off topology is 
consistent with the tooth contact area. This kind of contact area is very sensitive to the mounting errors and has no adjustable, so it needs to be mismatch modified.

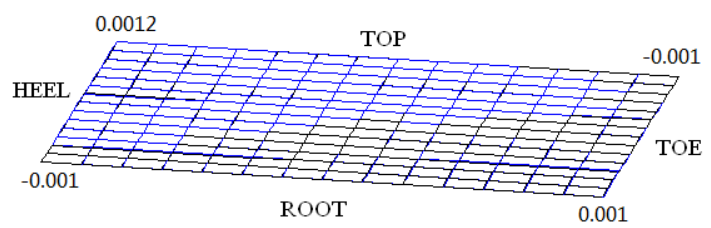

(a) Ease off for drive side (unit : $\mu \mathrm{m}$ )

$\mu \mathrm{m})$

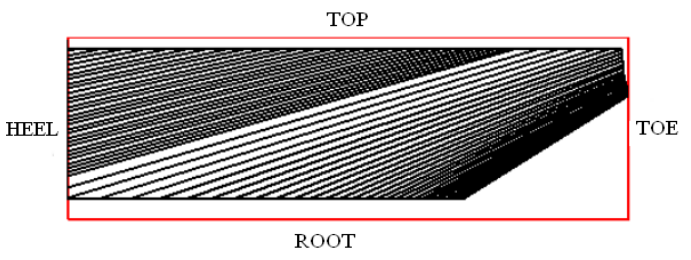

(c) Contact area for gear convex

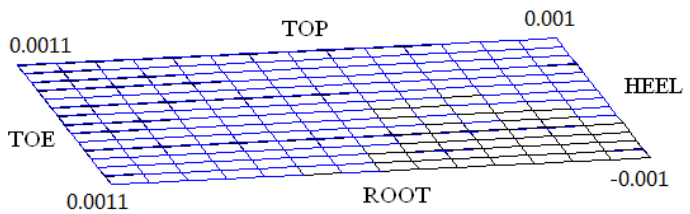

(b) Ease off for coast side (unit :

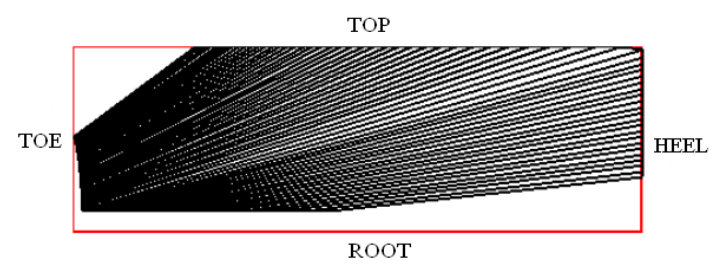

(d) Contact area for gear concave

Fig. 13 Tooth mismatch meshing analysis results for original cutting parameters

\subsection{The process of tooth surface modification}

Step 1: tooth length direction modification

In this paper, the mismatch modification of tooth length direction is realized by correcting the radius of cutter. Taking FN cutter head as the research object, the convexity value of cutter head $F=24$ is selected, and the revised cutter parameters are calculated according to the formula in Section 3.1, as shown in Tab.3.

Table 3 Modified cutter parameters

\begin{tabular}{l|c|c}
\hline \hline Name & Pinion & Gear \\
\hline $\begin{array}{l}\text { Group number of cutter } \\
\text { Nominal radius of cutter head } /(\mathrm{mm})\end{array}$ & 5 & 5 \\
$\begin{array}{l}\text { The direction angle of inner cutter in the } \\
\text { plane of tooth pitch point } /\left(^{\circ}\right)\end{array}$ & 90 & 11.6295 \\
$\begin{array}{l}\text { The direction angle of outer cutter in the } \\
\text { plane of tooth pitch point } /\left(^{\circ}\right)\end{array}$ & 11.4184 & 11.4184 \\
$\begin{array}{l}\text { Modification of radius of inner cutter in the } \\
\text { plane of tooth pitch point } /(\mathrm{mm})\end{array}$ & -0.8298 & -0.8298 \\
$\begin{array}{l}\text { Modification of radius of outer cutter in the } \\
\text { plane of tooth pitch point } /(\mathrm{mm})\end{array}$ & 0.8298 & 0.8298 \\
$\begin{array}{l}\text { Profile angle of inner cutter } /\left(^{\circ}\right) \\
\text { Profile angle of outer cutter } /\left(^{\circ}\right)\end{array}$ & 22.5 & 22.5 \\
\hline
\end{tabular}

After the radius of the cutter head is corrected, the tooth mismatch meshing simulation results are shown in Fig.14. As can be seen from Fig.14, after the radius of cutter head is corrected, the meshing tooth surfaces of gear and pinion mismatch in the direction of tooth length, and the fully conjugated tooth contact becomes the local contact. The tooth contact areas for gear convex and concave all lie in the middle of the tooth surface and slightly inclined to the heel position, and have slight bias out trend. The radius modification of cutter head only realizes the modification in the direction of tooth length, but no modification in the direction of tooth profile. At this time, the transmission error is 0 , which is still sensitive to the mounting errors, so the further modification is needed. 


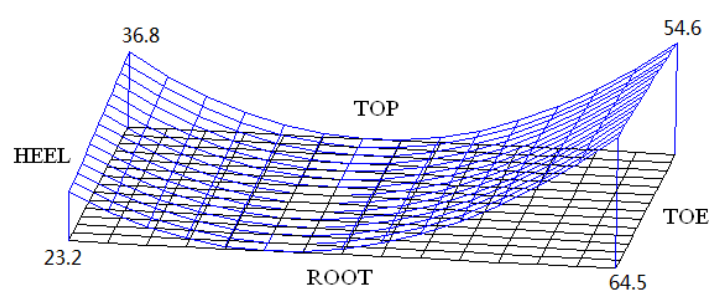

(a) Ease off for drive side (unit : $\mu \mathrm{m}$ )

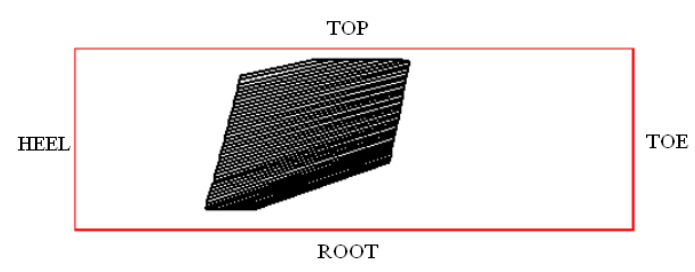

(c) Contact area for gear convex

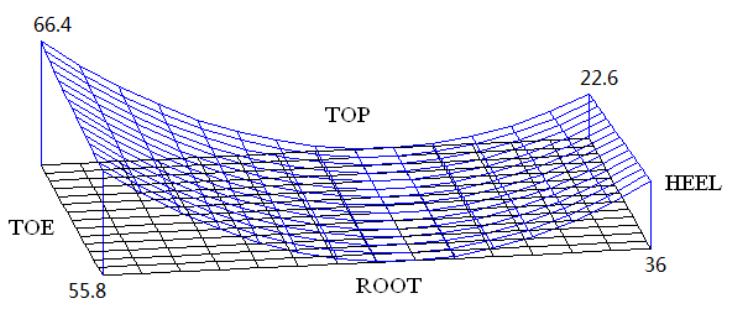

(b) Ease off for coast side (unit : $\mu \mathrm{m}$ )

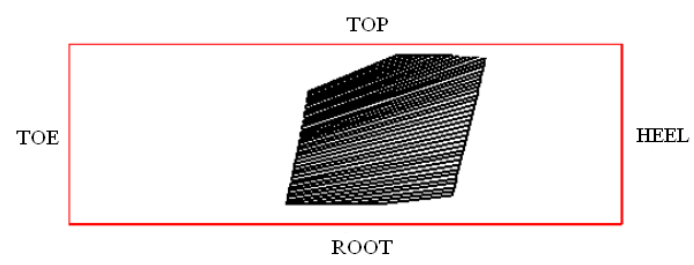

(d) Contact area for gear concave

Fig. 14 Tooth mismatch meshing analysis results after radius correction of cutter head

Step 2: tooth profile direction modification

In this paper, the shape of the cutter blade edge of pinion is modified into the arc blade edge to achieve the mismatch modification of the tooth profile direction. The arc curvature radius of pinion blade edge is $R_{H A}=2500 \mathrm{~mm}$ and $R_{H I}=2500 \mathrm{~mm}$, respectively. After the arc modification of the tooth profile, the tooth meshing simulation results are shown in Fig. 15.

On the basis of the radius correction of cutter head, the arc modification of the cutter blade edge of pinion is carried out again. It can be seen from Fig.15 that, the meshing tooth surfaces of the gear and pinion mismatch in the direction of tooth length and tooth profile. The tooth contact areas for gear convex and concave all changed from slight bias out trend to slight bias in trend, and the transmission error is also changed into the parabolic shape with the opening down, which reduces the sensitivity of mounting errors to a certain extent. Compared with Fig.14 and Fig.15, it can be seen that the meshing performance of tooth surface is improved after arc modification. But at the same time, it can be seen that the arc modification of cutter blade edge can correct the shape of the contact area and transmission error, but it does not change the position of tooth contact area, so the further modification is needed.

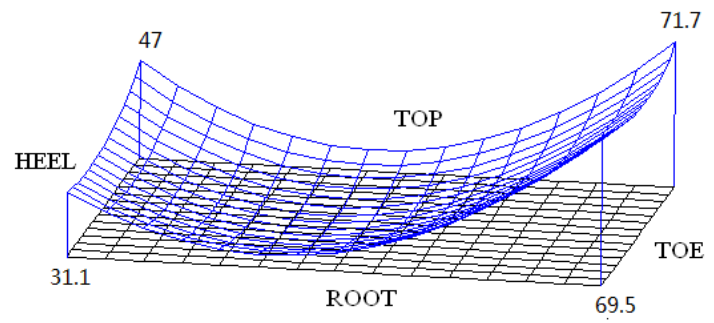

(a) Ease off for drive side (unit : $\mu \mathrm{m}$ )

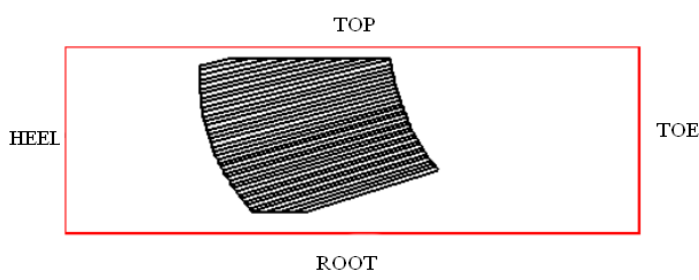

(c) Contact area for gear convex

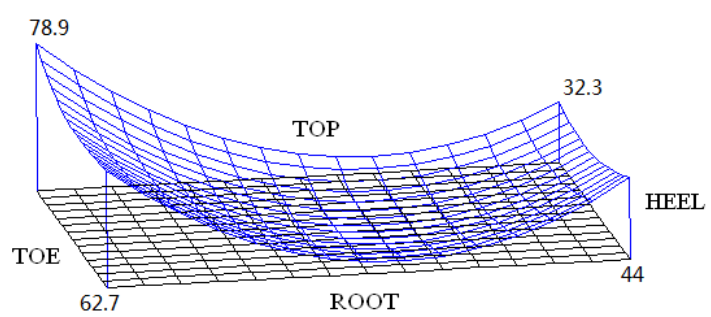

(b) Ease off for coast side (unit : $\mu \mathrm{m}$ )

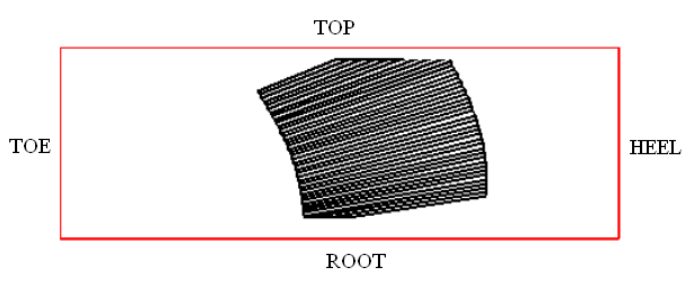

(d) Contact area for gear concave 


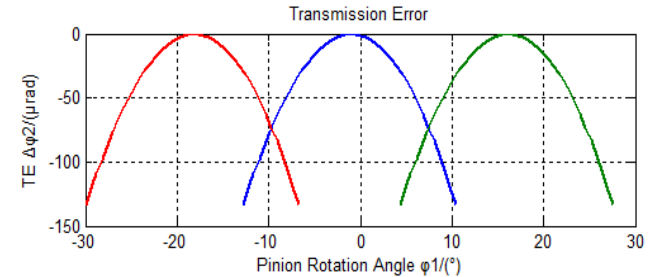

(e) Transmission error for drive side $\left(R_{H A}=2500 \mathrm{~mm}\right)$

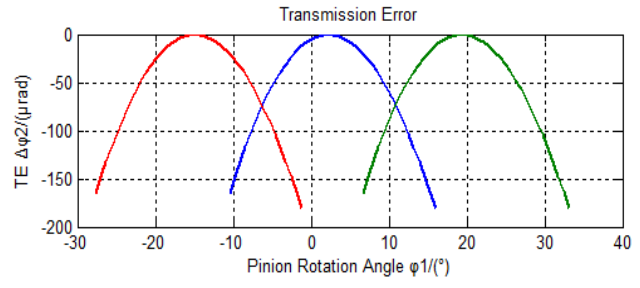

(f) Transmission error for coast side $\left(R_{H I}=2500 \mathrm{~mm}\right)$

Fig. 15 Tooth mismatch meshing analysis results after radius correction + arc modification of cutter

Step 3: tooth surface mismatch topology modification

According to the engineering requirements, we firstly formulate the requirements of tooth contact area: for drive side it requires that the tooth contact area should be located in the middle of the tooth surface and slightly inclined to the toe, showing a slight bias in trend, while for the coast side it requires that the tooth contact area should be located in the middle of the tooth surface with a slight bias in trend.

In order to obtain the required tooth contact area, the tooth surface mismatch relationship for step 2 needs to be modified again. The tooth surface mismatch coefficients obtained from the step 2 are shown in Tab.4. According to the requirement of tooth contact area, the modified mismatch coefficients of tooth surface are formulated, as shown in Tab.5. In this paper, it is assumed that the tooth surface of the pinion obtained in step 2 is defined as the pinion current tooth surface, and the tooth surface of pinion modified by the mismatch relationship is defined as the pinion target tooth surface. Figure16 shows the relationship between the pinion current tooth surface and pinion target tooth surface before and after the mismatch modification of tooth surface.

Table 4 Current tooth mismatch coefficients

\begin{tabular}{c|c|c|c|c|c}
\hline \hline Coefficient & $a_{\beta}$ & $a_{\alpha}$ & $a_{L}$ & $a_{H}$ & $a_{v}$ \\
\hline Drive side & -0.0007 & -0.0007 & 0.00011 & 0.0003 & 0.00001 \\
Coast side & -0.0007 & 0.0007 & 0.00011 & 0.0003 & -0.00005 \\
\hline
\end{tabular}

Table 5 Corrected coefficients of tooth surface mismatch

\begin{tabular}{l|c|c|c|c|cc}
\hline \hline Coefficient & $a_{\beta}$ & $a_{\alpha}$ & $a_{L}$ & $a_{H}$ & $a_{v}$ \\
\hline Drive side & 0.0008 & 0.0005 & 0.0001 & 0.0002 & 0.0000 \\
Coast side & 0.0000 & 0.0000 & 0.0001 & 0.0002 & -0.0001 \\
\hline
\end{tabular}

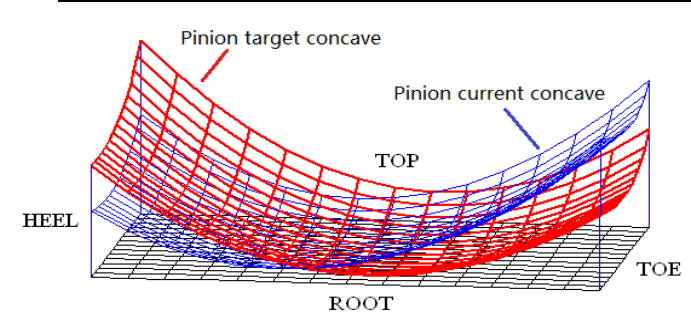

(a) The relationship between the pinion current concave and pinion target concave

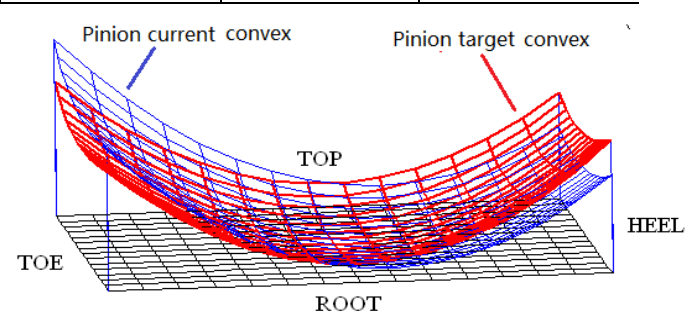

(b) The relationship between the pinion current convex and pinion target convex

Fig. 16 The relationship between the current tooth surface and the target tooth surface of pinion before and after tooth surface mismatch modification

According to the relationship between the pinion current tooth surface and pinion target tooth surface in Fig.16, the deviations between the pinion current tooth surface and pinion target tooth surface can be calculated. By eliminating the tooth surface deviations and making the pinion current tooth surface approach pinion target tooth surface, the processing parameters of pinion can be corrected, and the required tooth surface mismatch can be obtained. The modified processing parameters of pinion are shown in Tab.6. 
Jing Deng, Nie, Xiaozhong Deng and Jiang,

Journal of Advanced Mechanical Design, Systems, and Manufacturing, Vol.14, No.1 (2020)

Table 6 Modified processing parameters of pinion

\begin{tabular}{l|c|c}
\hline \hline Name & Parameters after modification & Modification values \\
\hline Tilt angle $/\left(^{\circ}\right)$ & -0.3524 & -0.3524 \\
Radial setting $/(\mathrm{mm})$ & 144.1701 & 0.2543 \\
Basic cradle angle/( $\left.{ }^{\circ}\right)$ & 35.5674 & -0.0040 \\
Vertical offset $/(\mathrm{mm})$ & 0.08675 & 0.08675 \\
Sliding base feed setting $/(\mathrm{mm})$ & -0.3771 & -0.3771 \\
Increment of machine center to back $/(\mathrm{mm})$ & 0.179 & 0.1790 \\
Machine root angle $/\left(^{\circ}\right)$ & 36.6851 & -0.1842 \\
Roll ratio & 1.670023 & 0.00337 \\
Profile angle of the inner cutter $/\left(^{\circ}\right)$ & 22.8698 & 0.3698 \\
Profile angle of the outer cutter $/\left(^{\circ}\right)$ & -21.952 & 0.5481 \\
Arc curvature radius of outer cutter $/(\mathrm{mm})$ & 2698.52 & 198.52 \\
Arc curvature radius of inner cutter $/(\mathrm{mm})$ & 2799.35 & 299.35 \\
\hline
\end{tabular}

The tooth surface of pinion is modified again by modifying the mismatch relationship of the tooth surface. According to the modified processing parameters of pinion in Tab.6, the tooth mismatch meshing analysis is carried out again, and the simulation results are shown in Fig.17.

It can be seen from Fig.17 that the position and shape of the tooth contact area meet the pre-determined requirements after tooth mismatch topology modification on the basis of step 2, and the shape of the transmission error has not changed significantly, and the parabolic shape of the opening downward is still maintained.

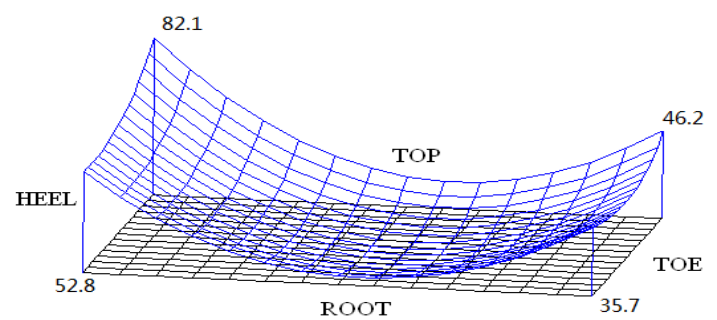

(a) Ease off for drive side (unit : $\mu \mathrm{m}$ )

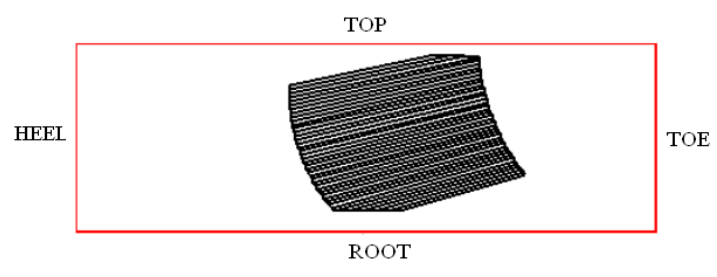

(c) Contact area for gear convex

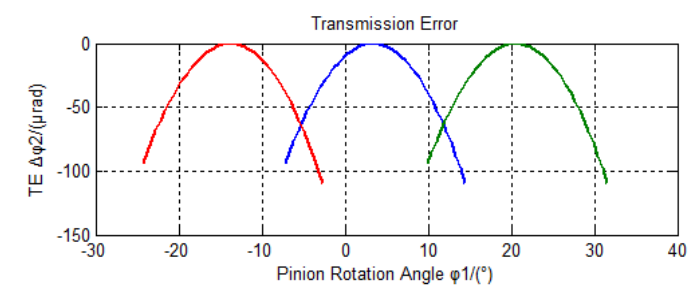

(e) Transmission error for drive side

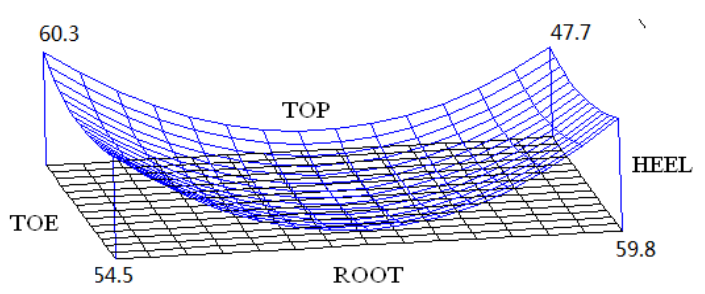

(b) Ease off for coast side (unit : $\mu \mathrm{m}$ )

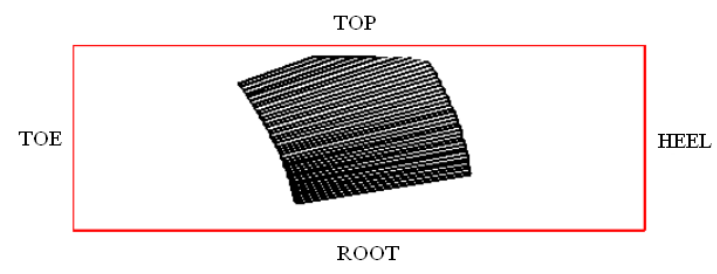

(d) Contact area for gear concave

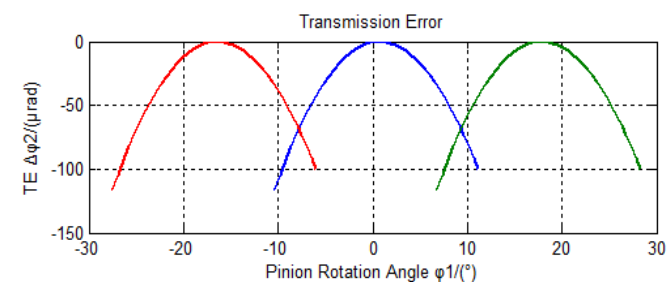

(f) Transmission error for coast side

Fig. 17 Tooth mismatch meshing analysis results after tooth mismatch topology modification 


\subsection{Cutting experiment}

In order to verify the correctness of the above simulation results, the gear cutting experiment and rolling test are carried out for the modification of step 1 to step 3. Figure18 shows the cutting experiments of gear and pinion, respectively. Figure 19 shows the actual tooth contact areas of each stage from step 1 to step 3. Fig.19(a) shows the actual tooth contact area after radius correction of cutter head for step 1,and Fig.19(b) shows the actual tooth contact area after radius correction and arc modification of cutter blade edge for step 2,and Fig.19(c) shows the actual tooth contact area after tooth mismatch topology modification for step 3. Because the tooth contact areas shown in Fig.19(a),(b) only consider the modification for the blade edge of cutter head, they represent the contact state before tooth mismatch topology modification.

From Fig.19(a), it can be seen that the actual tooth contact area for gear convex and concave after the radius correction of cutter head all lie in the middle of the tooth surface and slightly inclined to the heel position, and show slight bias out trend,which are consistent with the simulation results in Fig.14. From Fig.19(b), it can be seen that the actual tooth contact area for gear convex and concave after arc modification of cutter blade edge all lie in the middle of the tooth surface and slightly inclined to the heel position, and show slight bias in trend,which are consistent with the simulation results in Fig.15.From Fig.19(c), it can be seen that the actual tooth contact area for gear convex and concave after tooth mismatch modification all show slight bias in trend,for gear convex the tooth contact area position lies in the middle of the tooth surface and slightly inclined to the toe, and for gear concave the tooth contact area position lies in the middle of the tooth surface,which are consistent with the simulation results in Fig.17.Compared with Fig.19(a),(b) and Fig.19(c), it can be seen that the actual tooth contact area after tooth mismatch modification meets our requirement,and the tooth meshing performance is improved effectively.

All above comparison and analysis not only verify the simulation results correctness, but also indicate that the proposed tooth mismatch modification method in this paper can be used to improve the tooth meshing performance of cycloidal bevel gear effectively.

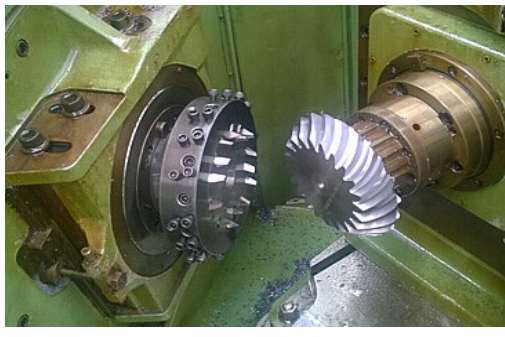

(a) Pinion cutting

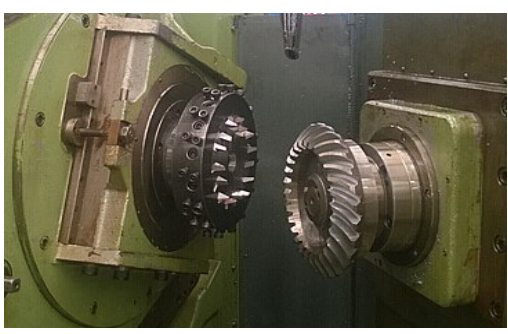

(b) Gear cutting

Fig. 18 Cutting experiments

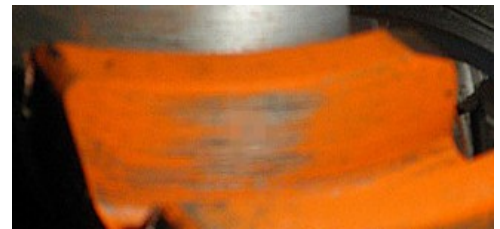

Contact area for gear convex

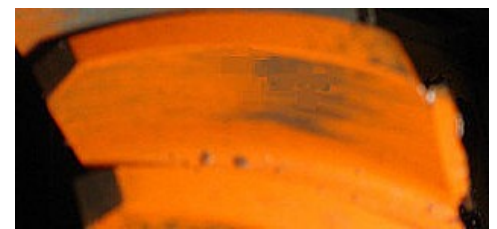

Contact area for gear concave

(a) Tooth contact area after radius correction of cutter head for step 1 (before tooth mismatch modification)

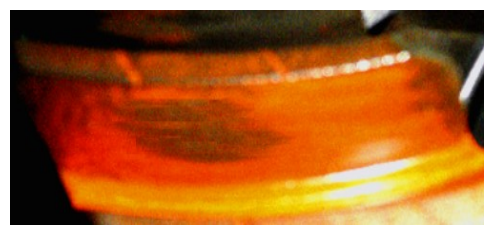

Contact area for gear convex

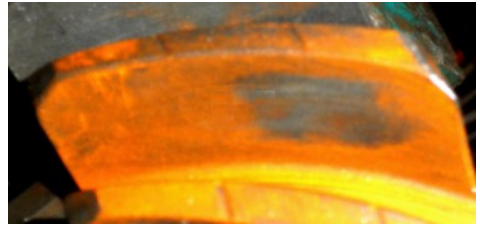

Contact area for gear concave

(b) Tooth contact area after radius correction and blade edge arc modification for step 2 (before tooth mismatch modification) 


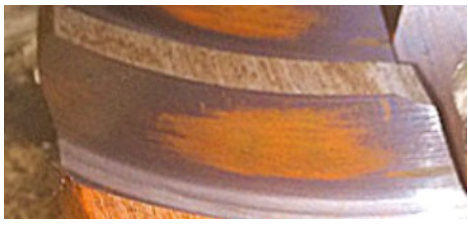

Contact area for gear convex

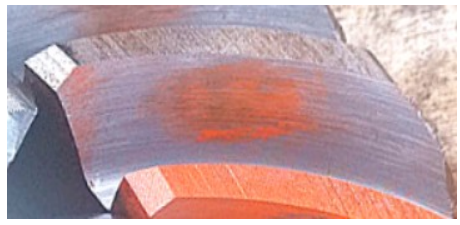

Contact area for gear concave

(c) Tooth contact area after tooth mismatch modification for step 3

Fig. 19 Actual tooth contact areas for step1 to step 3

\section{Conclusions}

1) Based on the fully conjugated characteristics of cycloidal bevel gear, a method of tooth surface mismatch modification is proposed in this paper. The double crowned modification of the tooth surface is realized by correcting the radius parameters of the cutter head and the arc modification of the cutter blade edge, which results in the double crown mismatch of the fully conjugated tooth surface in the direction of tooth length and tooth profile.

2) On the basis of cutter modification, this paper presents a method of tooth surface topology modification, which makes up for the shortcomings of cutter modification. By modifying the tooth surface mismatch relationship, the topography shape of pinion tooth surface can be modified more flexibly, and the required meshing performance of tooth surface can be obtained.

3) The validity and feasibility of the method proposed in this paper are verified by numerical simulation analysis and cutting experiments. This method can also be applied to the tooth surface modification of other gear systems.

\section{Acknowledgments}

The authors would like to thank the financial support from the National Natural Science Foundation of China (Grant Nos.51705134 and 51705135).We also thank anonymous reviewers and editors for their valuable comments and suggestions.

\section{Nomenclature}

$\begin{array}{ll}M & \text { reference point of tooth surface } \\ P_{0} & \text { pitch point of cutter } \\ r_{0} & \text { nominal radius of cutter head } \\ z_{0} & \text { tooth number of cutter head } \\ \delta_{0} & \text { direction angle of cutter edge } \\ \delta_{0 \prime} & \delta_{0 I} \quad \text { direction angle of inner cutter edge } \\ \delta_{0 A} & \text { direction angle of outer cutter edge } \\ \beta_{m 2} & \text { spiral angle of gear } \\ \beta_{p} & \text { spiral angle of generating gear } \\ z_{p 2} & \text { tooth number of generating gear } \\ R_{p} & \text { reference point cone distance of generating gear } \\ R_{m 2} & \text { reference point cone distance of gear } \\ \varepsilon_{02} & \text { deviation angle of gear cutting } \\ Z_{r 2} & \text { pitch apex distance of gear } \\ z_{2} & \text { tooth number of gear } \\ z_{1} & \text { tooth number of pinion }\end{array}$


$\delta_{2} \quad$ pitch angle of gear

$r_{m 2} \quad$ reference point radius of gear pitch circle

$E_{x 2} \quad$ radial setting of gear

$q_{2} \quad$ basic cradle angle of gear

$E_{m 2} \quad$ vertical offset of gear

$X_{b 2} \quad$ sliding base feed setting of gear

$X_{g 2} \quad$ increment of machine center to back of gear

$m_{p 2} \quad$ roll ratio of gear

$i_{p 2} \quad$ speed ratio of tooth dividing of gear

$\delta_{M 2} \quad$ machine root angle

$F \quad$ convexity value of cutter head

$\tau_{w} \quad$ intersection angle between the inner and outer blade edge

$\Delta \tau \quad$ intersection angle changes between the inner and outer blade edge

$\Delta s_{n p} \quad$ slot width changes

$\Delta r_{b} \quad$ modification of the tangential radius of cutter blade edge

$\Delta r_{b I} \quad$ modification of the tangential radius of inner cutter

$\Delta r_{b A} \quad$ modification of the tangential radius of outer cutter

$\alpha_{I} \quad$ profile angle of the inner blade edge

$\alpha_{A} \quad$ profile angle of the outer blade edge

$R_{H A} \quad$ radius of curvature of the outer arc blade edge

$R_{H I} \quad$ radius of curvature of the inner arc blade edge

$x_{t 1} \quad$ tangential modification factor

$j_{n} \quad$ backlash

$r_{b} \quad$ tangential radius of cutter head

$m_{n} \quad$ normal module of reference point

$r_{b i 1} \quad$ tangential radius of inner cutter of pinion

$r_{b a 1} \quad$ tangential radius of outer cutter of pinion

$r_{b i 2} \quad$ tangential radius of inner cutter of gear

$r_{b a 2} \quad$ tangential radius of outer cutter of gear

$P_{A} \quad$ pitch point of outer cutter

$P_{I} \quad$ pitch point of inner cutter

$H \quad$ plane of cutter blade edge

$T \quad$ pitch point plane of cutter head

$\chi_{1} \quad$ tilt angle of pinion

$J_{1} \quad$ basic swivel angle of pinion

$E_{x 1} \quad$ radial setting of pinion

$q_{1} \quad$ basic cradle angle of pinion

$E_{m 1} \quad$ vertical offset of pinion

$X_{b 1} \quad$ sliding base setting of pinion

$X_{g 1} \quad$ increment of machine center to back of pinion

$\delta_{M 1} \quad$ machine root angle of pinion

$\omega_{p 1} \quad$ angular velocity of generating gear

$\omega_{1} \quad$ angular velocity of pinion 


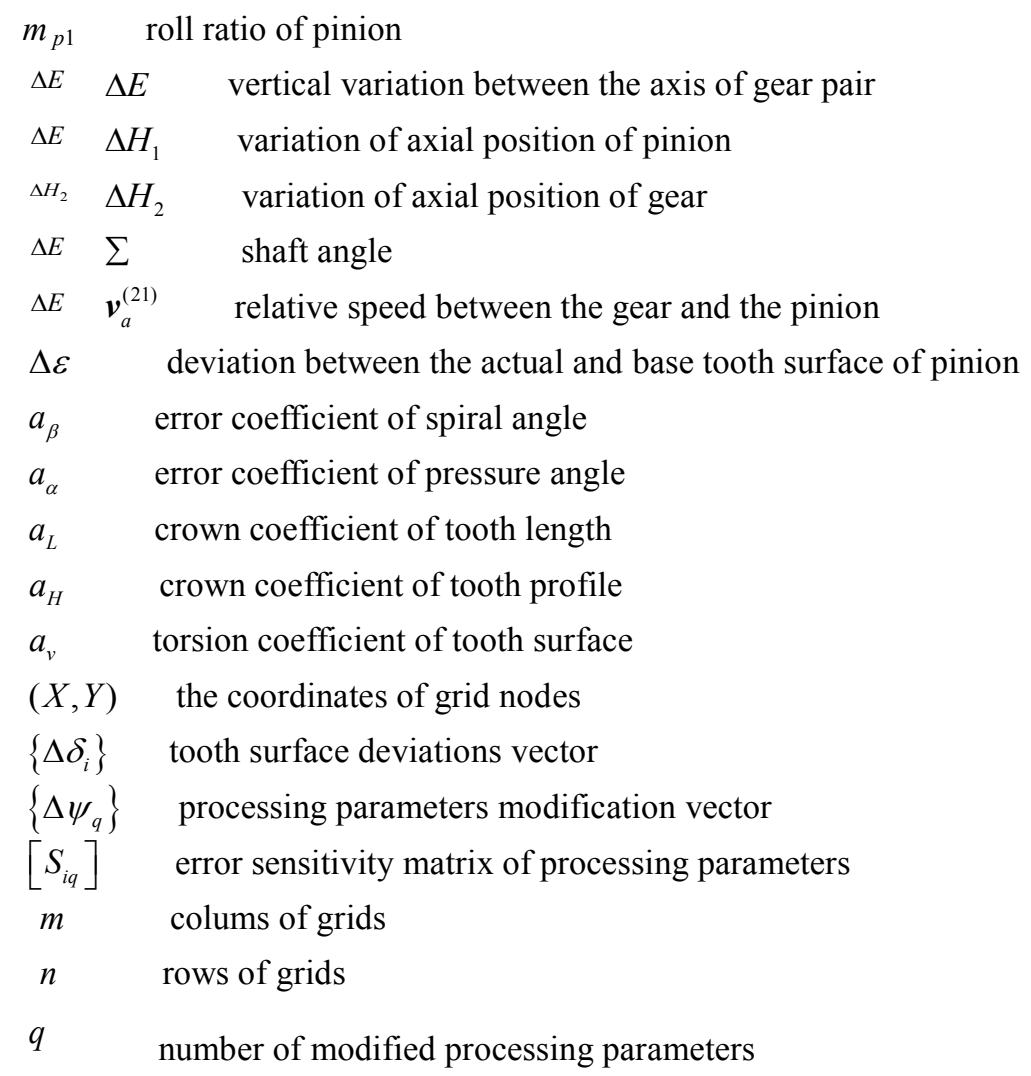

\section{References}

Alessio, A., Marco G., Mohsen K., Ease-off based compensation of tooth surface deviations for spiral bevel and hypoid gears: Only the pinion needs modifications, Mechanism and Machine Theory, Vol.61, No.3 (2013), pp.84-101.

Cao, X. M., Deng, X. Z., Nie, S. W., Ease-off flank topography design for aviation spiral bevel gears with higher-order transmission errors by modification of conjugate flank, Journal of Aerospace Power, Vol.30, No.1 (2015), pp.195-200.

Du, J. F., Fang, Z. D., Zhang, Y. Z., et al., Active tooth surface design of cycloid hypoid gears, Journal of National University of Defense Technology, Vol.37, No.6 (2015), pp.167-174.

Han, Z. Y., Deng, X. Z., Nie, S. W., et al., Influence of the modification of cycloid tooth bevel gear cutter head radius on the tooth surface contact performance, Journal of Mechanical Transmission, Vol.41, No.9 (2017), pp.6-10.

Huang, G., Research on the effects of spiral bevel gear's tooth surface modification on contact characteristics, Chongqing University of Technology, 2017.

Jiang, J. K., Fang, Z. D., Liu, Z., A design with multi-objective tooth optimization for hypoid gear with ease-off topological modification, Journal of Xi'an Jiaotong University, Vol.53, No.6 (2019), pp.1-8.

Jiang, J. K., Fang, Z. D., Su, J. Z., CNC grinding machining of topologically modified helical gear, Journal of South China University of Technology, Vol.42, No.4 (2014), pp.97-104.

Kolivand, M., Kahraman, A., A load distribution model for hypoid gears using ease-off topography and shell theory, Mechanism and Machine Theory, Vol.44, No.10 (2009), pp.1848-1865.

Li, J. C., Wang, T. Y., Fan, S. B., et al., Error modifications of spiral bevel gear tooth surface based on digitized manufacturing, Transactions of the Chinese Society for Agricultural Machinery, Vol.39, No.5 (2008), pp.174-177.

Liu, W. C., Liu, G. L., Contact analysis of spiral bevel gears based on parabolic blades, Machinery and Electronics, No.7 (2008), pp.13-15.

Nie, S. W., Deng, J., Deng, X. Z., et al., A flank modification method for spiral bevel gears based on mismatch topography adjustment, Journal of Advanced Mechanical Design Systems and Manufacturing, Vol.12, No.2 (2018), pp.1-15. 
Nie, S. W., Deng, J., Deng, X. Z., et al., Tooth surface error equivalent modification method of spiral bevel gears based on ease off topology, China Mechanical Engineering, Vol.28, No.20 (2017), pp.2434-2440.

Nie, S. W., Deng, J., Deng, X. Z., et al., Tooth surface topology modification and processing parameters calculation for spiral bevel gears, Journal of Aerospace Power, Vol.32, No.8 (2017), pp.2009-2016.

Nie, S. W., Deng, X. Z., Li, T. X., et al., Tooth meshing contact analysis for bevel gears by face hobbing method based on arc blade profile, Journal of Aerospace Power, Vol.27, No.6 (2012), pp.1424-1431.

Nie, S. W., Deng, X. Z., Su, J. X., et al., Flank modification simulation and high-order transmission error design for epicycloid bevel gears, Journal of Machine Design, Vol.30, No.5 (2013), pp.32-37.

Peng, X. L., Hu, X. W., Fang, Z. D., Active design of face gear drive for modifying ease-off topology flank, Journal of Aerospace Power, Vol.29, No.5 (2014), pp.1216-1222.

Shih, Y. P., A novel ease-off flank modification methodology for spiral bevel and hypoid gears, Mechanism and Machine Theory, Vol.45, No.8 (2010), pp.1108-1124.

Shih, Y. P., Fong, Z. H., Flank modification methodology for face-hobbing hypoid gears based on ease-off topography, Journal of Mechanical Design, Transactions of the ASME, Vol.129, No.12 (2007), pp.1294-1302.

Shih, Y. P., Fong, Z. H., Flank modification for spiral bevel and hypoid gears on a six-axis CNC hypoid generator, Journal of Mechanical Design, Transactions of the ASME, Vol.130, No.6 (2008), pp.0626041-06260411.

Su, J. Z., Fang, Z. D., Low sensitivity modification for spiral bevel gears, Journal of Aerospace Power, Vol.27, No.8 (2012), pp.1896-1901.

Su, J. Z., He, Z. X., High-precision modification of tooth surface for spiral bevel gears, Journal of South China University of Technology, Vol.42, No.4 (2014), pp.91-96.

Tang, J. Y., Nie, J. A., Wang, Z. Q., Reverse modification of spiral bevel gear HFT method, Journal of Central South University, Vol.43, No.6 (2012), pp.2142-2149.

Yan, H. Z., Wu, S. X., Xiao, M., Effect of tooth surface zoning modification by duplex helical method on reducing sensitivity of installation error, Journal of Central South University (Science and Technology), No.2 (2019), pp.286-294.

Zhang, Y., Yan, H. Z., Zeng, T., et al., Influence mechanisms between helical motion velocity coefficient and cutter parameters and characteristics of tooth surface generated by duplex helical method, Journal of Mechanical Engineering, Vol.54, No.5 (2018), pp.53-61. 